\title{
A genomic analysis and transcriptomic atlas of gene expression in Psoroptes ovis reveals feeding- and stage-specific patterns of allergen expression
}

Stewart T. G. Burgess ${ }^{1 *}$ D, Edward J. Marr ${ }^{1}$, Kathryn Bartley ${ }^{1}$, Francesca G. Nunn ${ }^{1}$, Rachel E. Down², Robert J. Weaver², Jessica C. Prickett ${ }^{2}$, Jackie Dunn², Stephane Rombauts ${ }^{3,4,5}$, Thomas Van Leeuwen ${ }^{6}$, Yves Van de Peer ${ }^{3,4,5,7}$ and Alasdair J. Nisbet ${ }^{1}$

\begin{abstract}
Background: Psoroptic mange, caused by infestation with the ectoparasitic mite, Psoroptes ovis, is highly contagious, resulting in intense pruritus and represents a major welfare and economic concern for the livestock industry Worldwide. Control relies on injectable endectocides and organophosphate dips, but concerns over residues, environmental contamination, and the development of resistance threaten the sustainability of this approach, highlighting interest in alternative control methods. However, development of vaccines and identification of chemotherapeutic targets is hampered by the lack of $P$. ovis transcriptomic and genomic resources.

Results: Building on the recent publication of the $P$. ovis draft genome, here we present a genomic analysis and transcriptomic atlas of gene expression in P. ovis revealing feeding- and stage-specific patterns of gene expression, including novel multigene families and allergens. Network-based clustering revealed 14 gene clusters demonstrating either single- or multi-stage specific gene expression patterns, with 3075 female-specific, 890 malespecific and 112, 217 and 526 transcripts showing larval, protonymph and tritonymph specific-expression, respectively. Detailed analysis of $P$. ovis allergens revealed stage-specific patterns of allergen gene expression, many of which were also enriched in "fed" mites and tritonymphs, highlighting an important feeding-related allergenicity in this developmental stage. Pair-wise analysis of differential expression between life-cycle stages identified patterns of sex-biased gene expression and also identified novel $P$. ovis multigene families including known allergens and novel genes with high levels of stage-specific expression.
\end{abstract}

Conclusions: The genomic and transcriptomic atlas described here represents a unique resource for the acaridresearch community, whilst the OrCAE platform makes this freely available, facilitating further community-led curation of the draft $P$. ovis genome.

Keywords: Psoroptes ovis, Sheep scab, Transcriptome, Life-cycle, Development, Allergens

\footnotetext{
* Correspondence: stewart.burgess@moredun.ac.uk

${ }^{1}$ Moredun Research Institute, Pentlands Science Park, Bush Loan, Edinburgh,

Midlothian EH26 OPZ, UK

Full list of author information is available at the end of the article
}

(c) The Author(s). 2019 Open Access This article is distributed under the terms of the Creative Commons Attribution 4.0 International License (http://creativecommons.org/licenses/by/4.0/), which permits unrestricted use, distribution, and reproduction in any medium, provided you give appropriate credit to the original author(s) and the source, provide a link to the Creative Commons license, and indicate if changes were made. The Creative Commons Public Domain Dedication waiver (http://creativecommons.org/publicdomain/zero/1.0/) applies to the data made available in this article, unless otherwise stated. 


\section{Background}

Psoroptic mange, caused by the ectoparasitic mite Psoroptes ovis, is characterised by pruritus and skin irritation and is a major welfare and economic concern for the livestock industry as the parasite infests both cattle and sheep, causing the disease "sheep scab" in the latter [1, 2]. In sheep, control relies on injectable macrocyclic lactone-based endectocides and organophosphate dips but concerns over residues, environmental contamination and the development of resistance threaten the sustainability of this approach and have highlighted interest in developing alternative control methods [3, 4]. However, the development of novel interventions (including vaccines and the identification of potential chemotherapeutic targets) has previously been hampered by a lack of detailed transcriptomic and genomic resources for $P$. ovis.

The integration of newly-available transcriptomic and genomic data with current knowledge of the basic biology of the mite is pivotal in the development of such novel interventions: The basic biology of the obligate ectoparasitic mite, $P$. ovis, on sheep is well understood, with the lifecycle taking place entirely on the ovine host and lasting from 11 to 19 days from egg hatch to egg production by the adult [5]. The life-cycle progresses from egg through four developmental stages (larvae $\rightarrow$ protonymph $\rightarrow$ tritonymph $\rightarrow$ adult (male/female)) (Fig. 1). Adult female mites can survive on the host for up to 42 days and during this time they may deposit up to 80 eggs $[1,6,7]$. Psoroptes ovis mites are able to survive for a limited time (15-16 days) off-host, enabling their transfer from animal to animal via fomites [8]. Psoroptes ovis is a non-burrowing mite, which feeds at the skin surface consuming serous exudate, lymph and red blood cells [9]. Mites survive on the surface of the skin and their mouthparts, which are thought to abrade rather than pierce the skin, do not penetrate beyond the stratum corneum, the outermost layer of the skin [10]. As the mites move across the surface of the skin they secrete and excrete allergens and other potent pro-inflammatory factors and this combination of mechanical skin abrasion, allergen deposition and grooming behaviour by the host in response to the pruritus caused by the mites all contribute to the subsequent cutaneous inflammatory response [1113]. However, the role of the different developmental stages of $P$. ovis in eliciting the pathology associated with the host pro-inflammatory response, and subsequent semiprotective immunity, is currently unknown and would be greatly improved with knowledge of the individual life-cycle stage transcriptomes.

Existing transcriptomic tools and resources for $P$. ovis are limited and include an expressed sequence tag (EST) survey of $\sim 500$ P. ovis cDNAs [14], a subtractive suppressive hybridisation (SSH) based comparison of gene expression between "fed" and "starved" P. ovis mites [15] and a cDNA microarray based on $\sim 1000$ P. ovis ESTs [16]. More recently a preliminary transcriptomic analysis of $P$. ovis var. cuniculi across a limited number of developmental

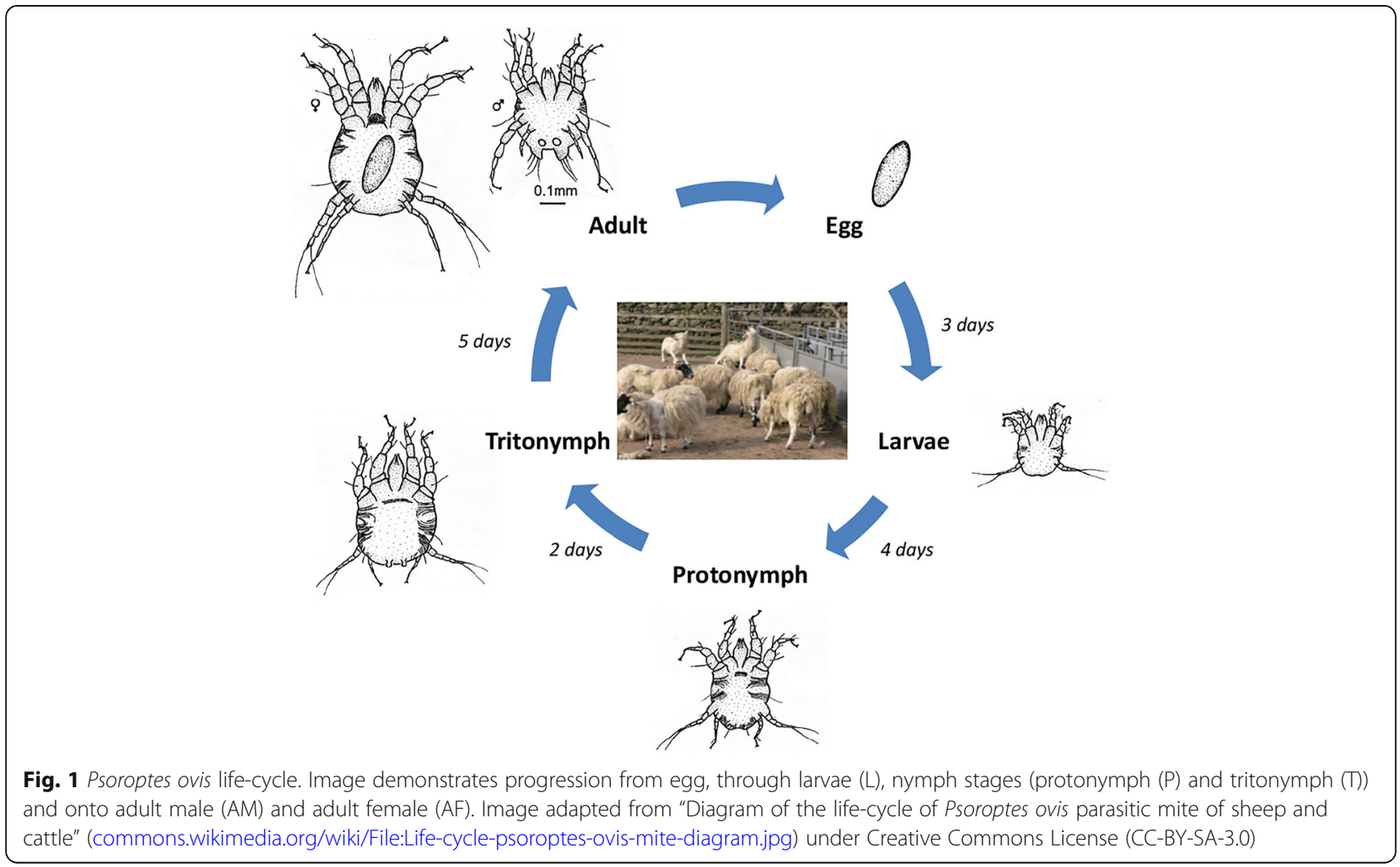


stage comparisons using Illumina RNA-seq was described [17]. The recent generation of the $P$. ovis genome, which included the prediction and annotation of the $P$. ovis transcriptome [18] has substantially improved the resources available and enables more detailed genomic and transcriptomic analyses of $P$. ovis. At $63.2 \mathrm{Mb}$, the draft genome assembly demonstrated that $P$. ovis has one of the smallest arthropod genomes sequenced to date, smaller than the genome of the two-spotted spider mite (Tetranychus urticae $(90 \mathrm{Mb})$ ) but comparable in size with the closely related house dust mite (HDM) genomes (Dermatophagoides farinae $(53.5 \mathrm{Mb})$ and $D$. pteronyssinus $(70.76 \mathrm{Mb}))$ and the ectoparasitic scabies mite (Sarcoptes scabiei $(56.2 \mathrm{Mb})$ ) [1822]. Herein, using the recently described $P$. ovis genome [18], we described the detailed annotation of the genome to Gene Ontology (GO) level along with a quantitative transcriptomic analysis of $P$. ovis gene expression across multiple life-cycle stages, providing for the first time a complete transcriptomic atlas of stage-specific and feeding-related gene expression in this economically-important ectoparasite of livestock.

\section{Results and discussion}

Functional annotation of the $P$. ovis predicted transcriptome derived from the draft genome

Overall, 12,041 predicted protein coding genes were identified in the $P$. ovis genome, which represented the first global survey of the $P$. ovis gene repertoire [18]. This represents $\sim 190$ genes per $\mathrm{Mb}$ for $P$. ovis, which is comparable to other closely related mite species, for example $T$. urticae (205 genes per Mb), S. scabiei (189 genes per Mb), D. farinae (306 genes per Mb) and D. pteronyssinus (177 genes per $\mathrm{Mb}$ ). Interproscan analysis resulted in further functional annotation for 9960 genes and significant BLAST hits against the National Center for Biotechnology Information (NCBI) non-redundant (nr) database (March 2018) were identified for 10,009 (83\%) genes. GO assessment was performed in Blast2GO resulting in the assignment of GO terms for 8681 (72\%) genes and functional annotation for 7614 (63\%) genes. Figure 2 shows the distribution of sequences per GO term across multiple classification levels and is presented as three pie-charts showing GO term distributions for Biological Process, Molecular Function and Cellular Component.

\section{Interactive web-based presentation of the entire $P$. ovis genome and gene expression atlas allows interrogation of individual genes and their stage-specific expression profiles}

The full annotation of the $P$. ovis genome has now been made publicly available via the Online Resource for Community Annotation of Eukaryotes (OrcAE) each gene has a gene-specific page, describing the full annotation available for that gene, including information relating to: gene function, GO terms, Pfam protein domains, protein homologues and significant BLAST hit data, gene structure, coding sequence, protein sequence and, where available, transcript evidence based on associated ESTs/cDNA data (Fig. 3) [23]. Each gene was assigned a unique loci identifier with the following format: psoviXXgYYYYY, where XX defines the scaffold ID and YYYYY denotes the specific location within the scaffold. As with most large-scale genome projects, the $P$. ovis genome relied upon a computational gene prediction and annotation pipeline and although we also incorporated additional RNA-seq data as transcript evidence in this process it is likely that some errors will remain. As such, continual manual curation of gene prediction and annotation remains a critical step in assessing and improving gene prediction accuracy and overall confidence in the genome [24]. To facilitate this, the OrcAE platform is unique in that it also provides the tools and information for community-led manual validation of gene annotations.

\section{$P$. ovis collection, life-cycle staging and preparation of "fed" and "starved" mite populations}

Staging of $P$. ovis into individual life-cycle stages (Fig. 1) is challenging and time-consuming but can be performed with a high degree of accuracy [25]. Whilst staging of adult males (length: $396 \mu \mathrm{m}$, width: $380 \mu \mathrm{m}$ ) and females (length: $536 \mu \mathrm{m}$, width: $467 \mu \mathrm{m})$ was relatively straightforward by size alone, staging of larvae relied on identification by size (length: $250 \mu \mathrm{m}$, width: $212 \mu \mathrm{m}$ ) and the presence of three pairs of legs (rather than the four found in nymphs and adults). The relatively small size of larvae also required the collection of high numbers of individuals to allow recovery of sufficient RNA for sequencing. Separation of the nymph stages: protonymphs (length: $309-313 \mu \mathrm{m}$, width: 292-351 $\mu \mathrm{m}$ ) and tritonymphs (length: $402-414 \mu \mathrm{m}$, width: $370-436 \mu \mathrm{m}$ ) was partially achieved by size, but also relied on the identification of key morphological differences as highlighted in the taxonomical key provided by Sanders et al [25]. In total 1479 Adult Females, 1618 Adult Males, 3676 Larvae, 1814 Protonymphs and 1194 Tritonymphs were individually staged and collected. The "fed" and "starved" $P$. ovis mite samples $(n=3 /$ each $)$ were taken from the same mixed population, prior to staging and split into 3 pools.

\section{RNA extraction and quality control}

For each life-cycle stage and for the "fed" and "starved" conditions, the mites were divided into three equal-sized pools and high quality RNA was extracted from each pool, yielding $>10 \mu \mathrm{g}$ total RNA ( $5 \mu \mathrm{g}$ of which was used for the generation of each RNA-seq library) and RNA integrity numbers (RIN values) of greater $>7.5$ were obtained for each sample. 

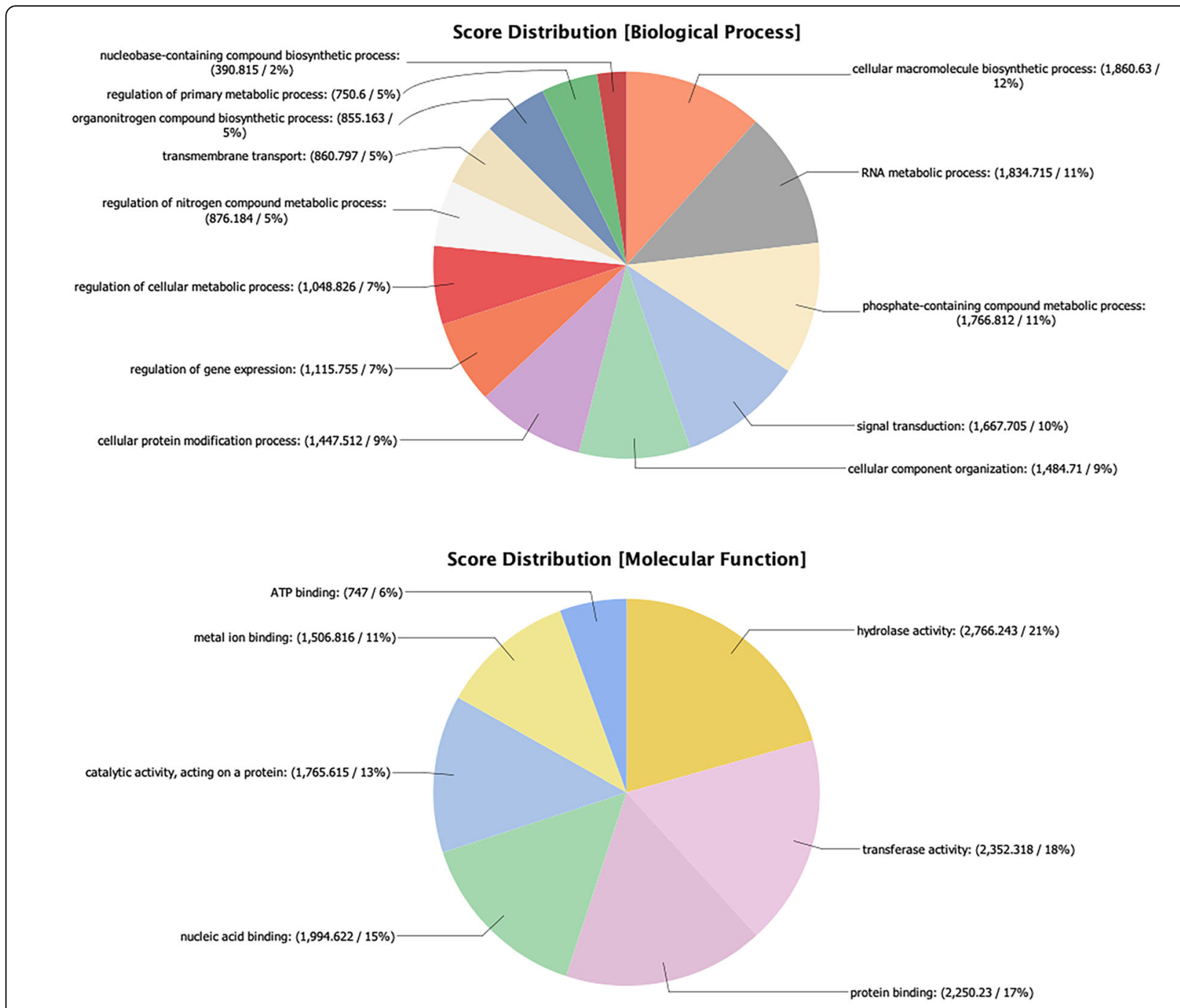

Score Distribution [Cellular Component]

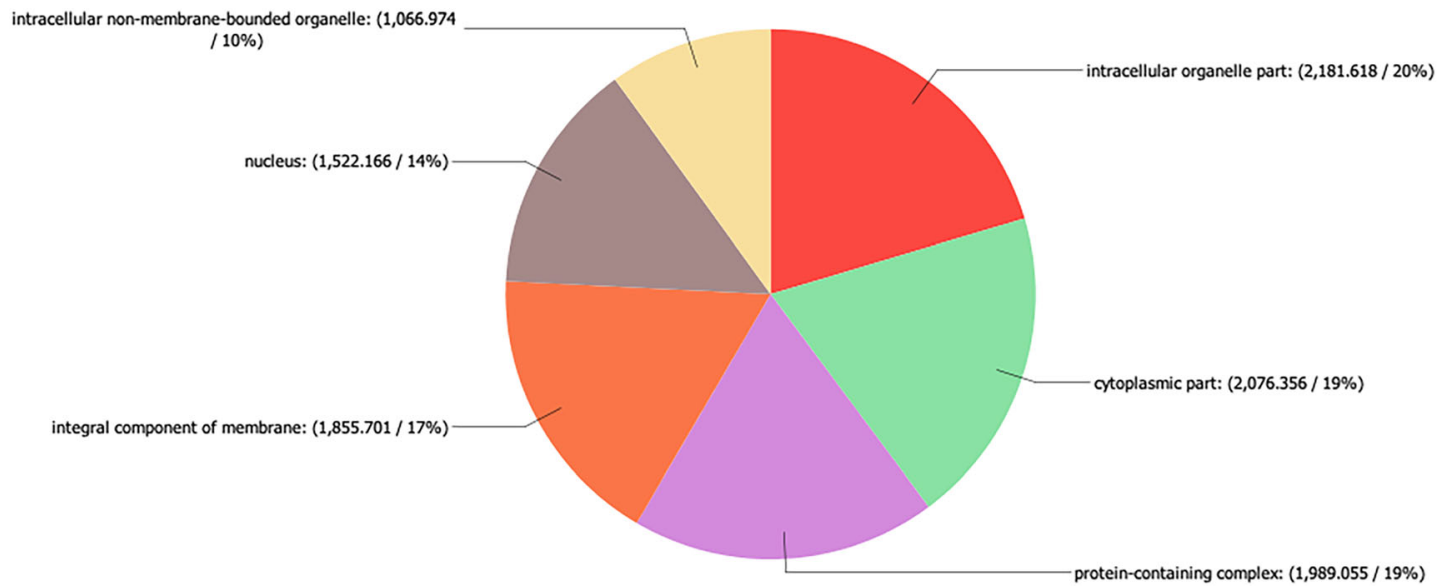

Fig. 2 Psoroptes ovis genome GO annotation. Each chart shows the multilevel distribution of sequences per GO term. Distribution of GO terms are summarised across three main categories: Biological Process, Molecular Function and Cellular Component 


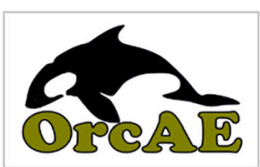

\section{ONLINE RESOURCE FOR COMMUNITY ANNOTATION OF EUKARYOTES}

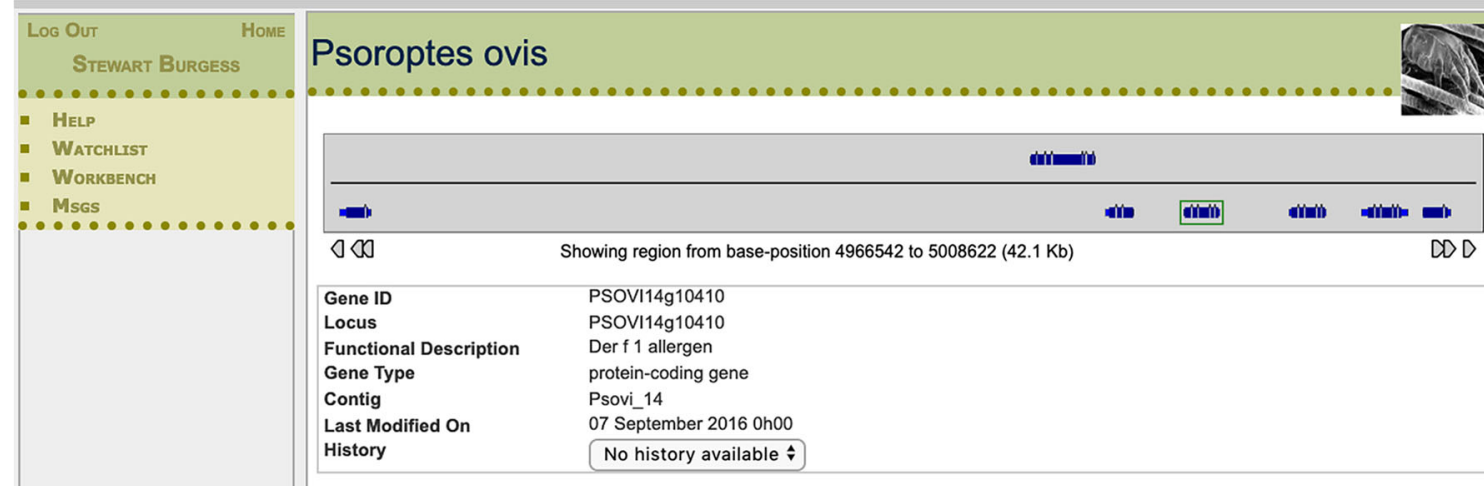

Modify This Record
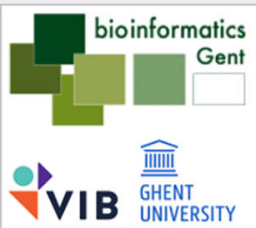

eli. ir $_{\text {BELGIUM }}$ GHENT UNIVERSITY

Contact:

Bioinformatics Gent

Principal Investigator:

Yves Van de Peer

ORCAE Technical Support: BEG-ORGAE

Name EuGene Automatic Prediction

Email beg-orcae@psb.ugent.be

Lab UGent

Status active

Gene Actions ?

Inactivate

Compare current version with :

Inactivate Gene

No history available $\hat{\forall}$ Go!

Gene Function (8)

Short Name

Alternative Names

Definition

Der $f 1$ allergen

Additional Functional Descriptiớ

Pubmed ID

EC Number

KOGid

n/a

n/a

Read Counts ?

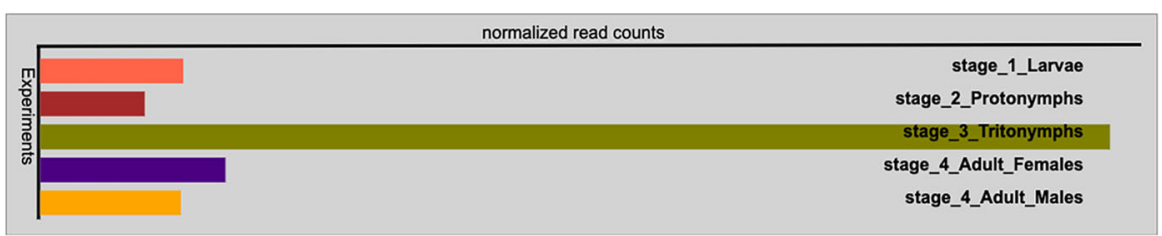

Gene Ontology ?

\begin{tabular}{|lll|}
\hline Cellular Component & n/a & \\
Molecular Function & 1. GO:0008234 & cysteine-type peptidase activity \\
Biological Process & 1. GO:0006508 & proteolysis \\
\hline
\end{tabular}

Biological Process

1. GO:0006508 proteolysis

Protein Domains (2)

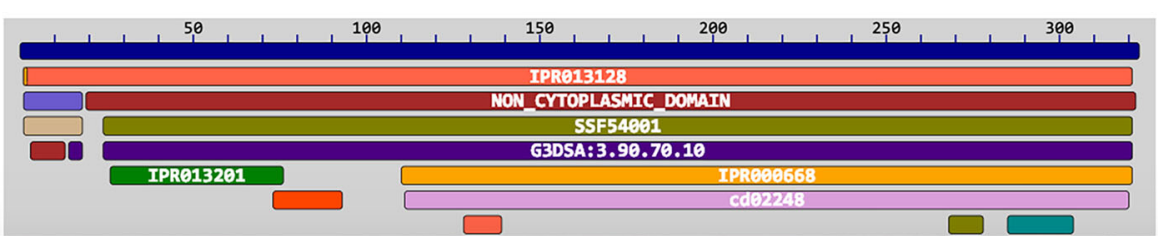

Fig. 3 Example page of the web-based $P$. ovis gene expression atlas. The atlas was constructed within the Online Resource for Community Annotation of Eukaryotes (OrcAE) framework [23]. Here we show the gene-specific page for the major P. ovis allergen, Pso o 1 (psovi14g10410). Website: http://bioinformatics.psb.ugent.be/orcae/overview/Psovi 
RNA-seq profiling of $P$. ovis stage-specific and feedingrelated gene expression

Illumina sequencing resulted in 8-26 million raw sequence reads for each of the twenty one sequencing libraries (three biological replicates for each of the five life-cycle stages and three each for "fed" and "starved" mites) with a mean of 13.7 million reads per sample (Additional file 1: Table S1). For each replicate, from each developmental stage we generated a set of expression estimates from the trimmed reads, as transcripts per million (TPM) using the transcript quantification tool Kallisto (Version 0.44.0 [26]) and the predicted transcriptome derived from the $P$. ovis genome [18]. The average percentage of pseudo-aligned reads across the 21 RNA-seq libraries was $82.9 \%$ (Additional file 1: Table S1).

\section{Network analysis and clustering of stage-enriched gene expression in $P$. ovis}

To identify groups of genes whose expression is associated with either single- or multiple-developmental stages of $P$. ovis, we performed a network graph analysis. It is well characterised that genes playing distinct roles in common signalling pathways or biological processes often share similar patterns of expression and therefore regulation [27]. As such, when genes are found to have similar expression profiles across multiple samples or sample classes, i.e. they are co-expressed, this may be an indication that they share functional or biological activity, i.e. guilt-by-association/ guilt-by-profiling [28]. Read count data, expressed as TPM, for each replicate, from each life-cycle stage was used to generate a gene-gene network graph within the Graphia Professional package [29]. The network graph was generated using a Pearson correlation cut-off of 0.9, resulting in a graph with 10,655 nodes (genes) connected by 3,451,719 edges. Individual genes were clustered using a Markov Cluster Algorithm (MCL) inflation value of 2.2, resulting in a final gene-to-gene network graph consisting of 7719 genes divided across 50 clusters (Fig. 4). The resulting network graph consisted of nodes (genes) connected by virtue of the similarity of their gene expression profile across each of the $P$. ovis life-cycle stages (Fig. 4). Amongst the 50 gene clusters within the network, a number of clusters demonstrated similar patterns of expression across the $P$. ovis life-cycle stages and these were further collated into groups of clusters. This resulted in a final total

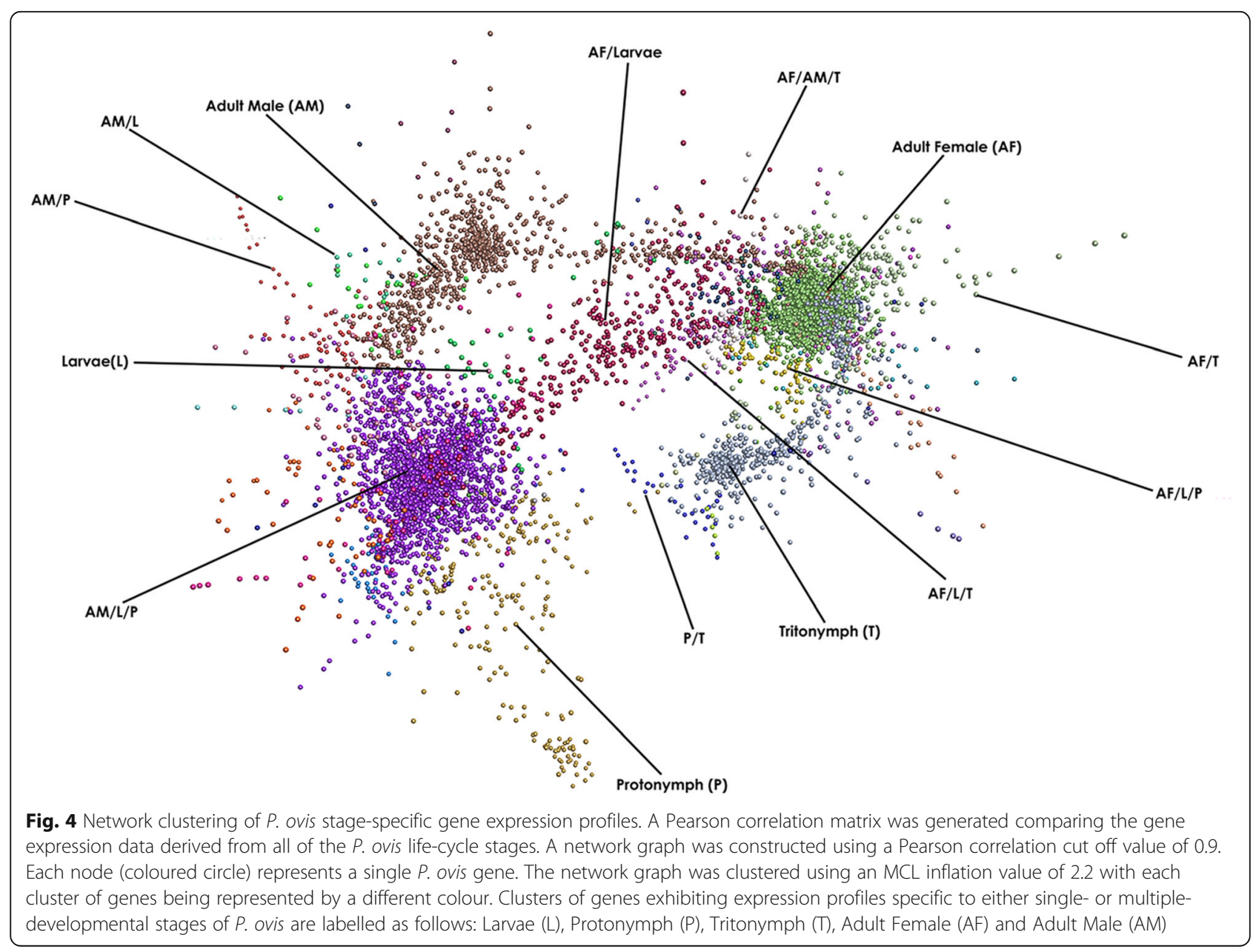


of 14 gene clusters (Table 1) demonstrating either single- or multi-stage enriched gene expression patterns (Fig. 5). The genes attributed to each individual cluster are listed in Additional file 2.

\section{Functional annotation of $P$. ovis stage-specific gene expression clusters}

The genes within each cluster were then mapped back to the original $P$. ovis genome annotation [18] and a GO analysis was performed within the Blast2GO package to identify associated GO terms for molecular function, biological process and cellular component attributed to each cluster.

\section{Genes enriched in $P$. ovis adult females (AF) - cluster 1}

Similar to other mite species, $P$. ovis exhibits sexual dimorphism, with clear morphological and behavioural differences existing between adult males and females and potentially also during the tritonymph stage [5]. In the fruit fly Drosophila melanogaster, many of these sexrelated changes have been attributed to differences in gene expression, suggesting that sexual dimorphism may result primarily from the differential expression of genes present in both sexes, e.g. sex-biased gene expression [30-32]. Here we investigated the differential expression of genes between adult male and adult female $P$. ovis mites to elucidate the mechanisms underlying this sexual dimorphism. Clustering analysis identified a cluster of 3075 genes showing adult female-enriched patterns of gene expression, which represents the largest cluster of stage-specific genes identified in this study. Amongst these, genes encoding $P$. ovis homologues of vitellogenin (psovi09g01710), vitellogenin receptor (psovi63g00310) and two group 14 apolipophorin allergens (psovi73g00070 and psovi35g00110) were present. Analysis of abundantlyexpressed genes in each individual life-cycle stage also reflected the stage-specific expression of vitellogenin and the vitellogenin receptor in the top 100 differentiallyexpressed genes in female mites (Additional file 3). Each of these genes has a role in oogenesis and all showed almost exclusive expression in the female mites. In addition, a number of genes encoding proteins involved in lipid metabolism, including an alkylglycerol monooxygenase-like protein (psovi288g00950), a perilipin-like protein (psovi66g00530), an ATP-binding cassette transporter (ABCA1) lipid exporter protein (psovi284g05730) were present along with 14 genes encoding proteins involved in the elongation of long chain fatty acids. The ABCA1 homologue was amongst the top 100 differentially-expressed genes in female mites (Additional file 3), and may have a role in lipid transport and more specifically in the removal of cholesterol from cells [33-35]. The expression of genes involved in lipid processing pathways in the adult females may indicate a role in nutrition related to supply of nutrients to reproductive tissues. Lipids represent a major constituent of the sheep epidermis and $P$. ovis is likely to use the abundant supply of lipids as an energy-rich food source [13, 36, 37]. One of the most highly expressed female-enriched genes encodes a putative serine protease inhibitor (Serpin) leukocyte elastase inhibitor-like protein (psovi22g04610, named Pso o 27 herein) homologous to both the newly-characterised HDM Der f 27 allergen and to a scabies mite (S. scabiei) serpin SMSB4, which has been shown to interfere with host complement-mediated neutrophil functions and promote staphylococcal growth during infestation with S. scabiei [38, 39]. A further four uncharacterised and highly expressed genes (psovi09g01110, psovi72g00350, psovi08g00890

Table 1 Description of final P. ovis stage-specific gene expression clusters $(n=14)$

\begin{tabular}{lll}
\hline Cluster ID & Predominant expression pattern & Number of genes in cluster (Rank) \\
\hline 1 & Adult Female (AF) & $3075^{(1)}$ \\
2 & Adult Male (AM) & $890^{(3)}$ \\
3 & Larvae (L) & $112^{(10)}$ \\
4 & Protonymph (P) & $217^{(7)}$ \\
5 & Tritonymph (T) & $526^{(4)}$ \\
6 & AF/L & $358^{(5)}$ \\
7 & AF/T & $45^{(12)}$ \\
8 & AF/L/P & $144^{(9)}$ \\
9 & AF/L/T & $270^{(6)}$ \\
10 & P/T & $5^{(14)}$ \\
11 & AF/AM/T & $145^{(8)}$ \\
13 & AM/L/P & $1834^{(2)}$ \\
\hline
\end{tabular}




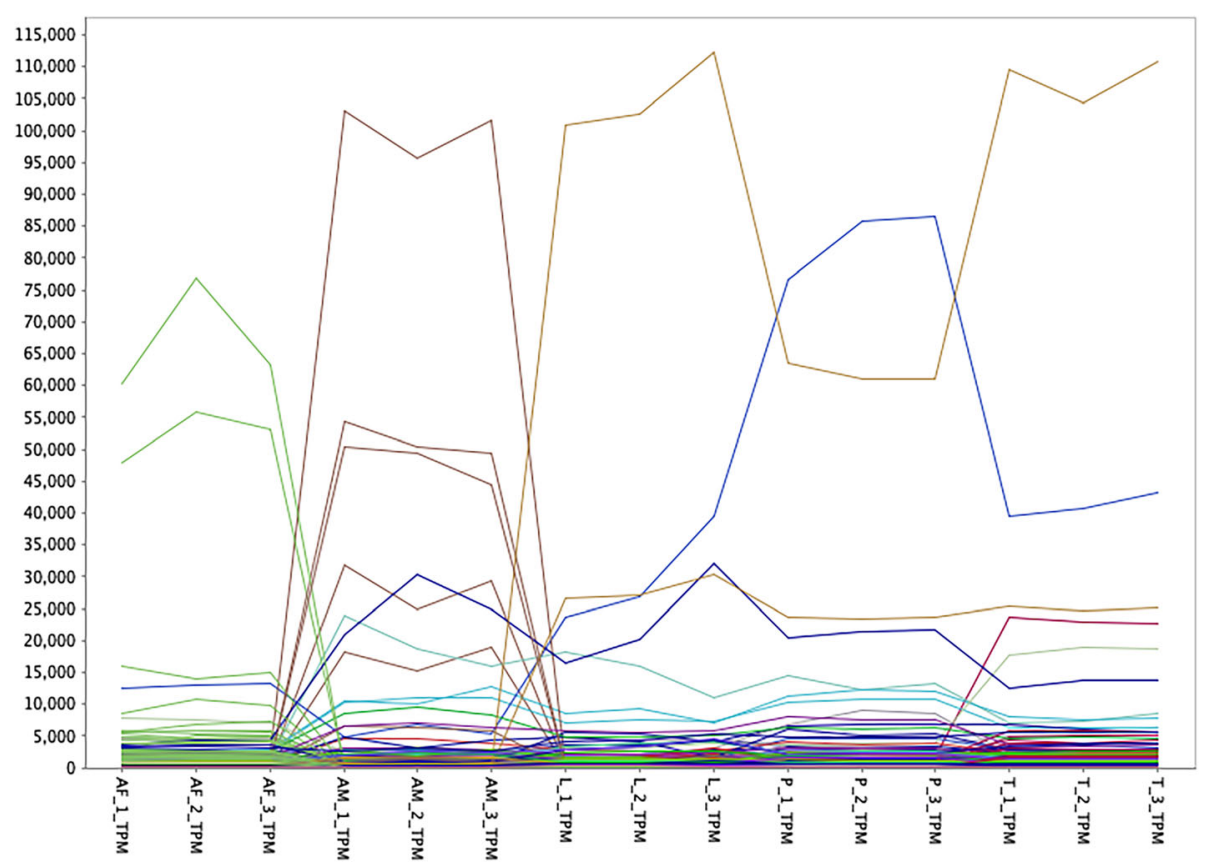

Fig. 5 Line plot showing $P$. ovis stage-specific gene expression profiles. Each line represents the expression profile of a single gene across triplicate samples for each P. ovis life-cycle stage: colours indicate individual gene clusters: Adult Female (AF), Adult Male (AM), Larvae (L), Protonymph (P), Tritonymph (T). Y-axis shows read count values expressed as transcripts per million (TPM) as derived from Kallisto (Version 0.44.0 [26])

and psovi06g00980) showed almost exclusive expression in the female mites. However, no significant BLAST hits were identified for these genes, indicating that they may represent unique $P$. ovis genes of as yet unknown function. A further female-enriched gene (psovi14g01150) showed a significant BLAST hit against a skin secretory protein, xP2-like from the African clawed frog, Xenopus laevis and the scallop Mizuhopecten yessoensis. This gene encodes a protein with a Trefoil (P-type) domain; a cysteine-rich domain consisting of approximately 45 amino-acids found in selected extracellular eukaryotic proteins [40]. The Trefoil domain has been identified as one of a relatively small number of protein families that represent potential allergens [41], as such the nature of this $P$. ovis gene and its role in the pro-inflammatory/allergic type response in psoroptic mange warrants further investigation. A final group of genes co-located in the female-enriched cluster are putative heat shock proteins (Hsp) with ten genes representing potential Hsps including $10 \mathrm{kDa}, 60 \mathrm{kDa}, 70 \mathrm{kDa}, 83 \mathrm{kDa}$ and $90 \mathrm{kDa}$ protein encoding genes. Hsp70 has been identified as an important allergen from sesame seed and hazel pollen [42] and has also been shown to be upregulated in the honey bee-parasitic mite, Varroa destructor following thermal stress and exposure to acaricide, indicating a potential role in xenobiotic metabolism [43].
Genes enriched in $P$. ovis adult males (AM) - cluster 2

Network clustering analysis identified 890 genes showing an adult male-enriched pattern of gene expression. Many of the genes in this cluster play a role in muscle development and function including genes encoding paxillins, muscle LIM proteins, PDZ and LIM domain containing proteins, alpha actinin, microtubule actin cross-linking factor, vinexins, paramyosin, vinculin, titin and calmodulin. Many of these are involved in the formation and contraction of muscle fibres and may reflect the increased motility of $P$. ovis males, compared to adult female mites [44]. This cluster also contained 19 highly expressed genes with an average read count of $>1000$ in the males, many of which currently represent uncharacterised genes with no known homologues (Additional file 3). Perhaps the most interesting of these are a group of three genes, co-located on the largest scaffold (Psovi_22) of the P. ovis genome (psovi22g004350; psovi22g004360 \& psovi22g004380) all of which are highly expressed in male mites. All three genes encode short proteins of $\sim 19 \mathrm{kDa}$ (166-169 amino acids) two of which (psovi22g004360 \& psovi22g004380) share 69\% identity at the amino acid level. In part, the presence of these highly expressed genes within potential multigene families may be explained by previous studies in $D$. melanogaster, where it has been shown that genes demonstrating a male-biased pattern of expression often exhibit greater differences in gene expression 
levels than that observed for female-biased genes or for non-sex-biased genes $[45,46]$. In addition, the rates of evolution at the sequence level observed in sex and reproduction-related (SRR) and non-SRR genes in D. melanogaster also differs, with male and female SRR genes evolving more rapidly than non-SRR genes [47-50]. In addition, Connallon and Knowles [30] showed that the majority of this sex-biased gene expression was due to adaptive changes in the males, suggesting they may experience stronger selection pressures than the females.

\section{Genes enriched in $P$. ovis larvae $(\mathrm{L})$ - cluster 3}

The cluster of larvae-enriched genes represents one of the smallest single-stage clusters with 112 genes. The most highly expressed gene in the cluster (see Additional file 3), showed very similar levels of expression in both larvae and tritonymphs and shares significant homology with a novel gene of unknown function from the HDM D. farinae [51]. The protein encoded by this gene was termed Dermatophagoides farinae most abundant protein 2 (DFP2) and as yet remains uncharacterised [51]. Two further highly expressed genes in this cluster encode $P$. ovis homologues of an ADP/ATP translocase (psovi43g01550) and a chaperonin containing TCP1 complex protein (CCT1) (psovi283g00230). CCT1 forms part of a chaperonin complex consisting of two identical stacked rings, each containing eight different proteins [52]. The completed complex functions in an ATP-dependent manner and is responsible for folding a range of proteins, including actin and tubulin [53].

\section{Genes enriched in $P$. ovis protonymphs $(P)$ - cluster 4}

Clustering analysis identified 217 genes showing a protonymph-enriched pattern of gene expression. Seventeen genes in this cluster shared significant homology with the HDM, DFP2 gene, as described above. However, the present study shows, for the first time, that multiple copies of this gene may exist in the $P$. ovis genome and analysis of abundantly-expressed genes in each individual life-cycle stage demonstrated that many of these are highly expressed across the juvenile stages (including, larvae, protonymphs and tritonymphs, see Additional file 3). The GO analysis demonstrated that, for the protonymph-enriched cluster, $22 \%$ of genes in the Biological Process category are associated with chitin metabolic processes, whilst $13 \%$ of genes in the Molecular Function category are involved in chitin binding, equating to 22 and 14 genes, respectively. Of these, specific functional annotation for chitin binding and metabolism was available for 12 genes, including a putative $P$. ovis chitin synthase (psovi294g01310), a chitin deacetylase (psovi33g00850), five chitinase homologues (psovi14g06600, psovi05g01800, psovi14g09170, psovi283g03530 and psovi20g01930) and five chitin binding peritrophin-like genes (psovi14g06590, psovi14g10800, psovi14g06580, psovi286g01240 and psovi284g00080). The same cluster also contained seven genes encoding putative cuticle proteins, all of which are highly expressed across the juvenile stages and not just the protonymphs. The presence of many highly expressed cuticle and chitin binding transcripts across the juvenile stages, indicates a role in the formation and/or moulting of the mite cuticle. This cluster also contained a further putative serpin with homology to the SMSB3 serine protease inhibitor from S. scabiei (psovi22g04600) which has a role in inhibition of host complement during scabies mite infestation [54]. Interestingly, this gene is co-located adjacent to the female-specific serpin described above (Pso o 27) with the predicted proteins from these two genes sharing $\sim 30 \%$ identity at the amino acid level. A further cluster (Cluster 10) contained five genes with an expression profile enriched in both protonymphs and tritonymphs and these represent two further DFP2 homologues, two putative cuticle proteins and one uncharacterised gene (Additional file 3).

\section{Genes enriched in $P$. ovis tritonymphs $(\mathrm{T})$ - cluster 5}

Clustering analysis identified 526 genes demonstrating tritonymph-enriched patterns of gene expression. GO analysis showed that for the tritonymph-enriched cluster, a large proportion (53\%) of the genes in the Molecular Function category were involved in enzyme activities, including proteolysis (8\%), transferase activity (12\%), hydrolase activity (20\%) and oxidoreductase activity (13\%). A similar pattern was observed for the Biological Process category with $16 \%$ of genes involved in oxidationreduction processes and $10 \%$ in proteolysis. In total, 73 of the 526 genes in this cluster (14\%) were assigned Enzyme Commission (EC) codes, distributed as follows: hydrolases $(n=27)$, oxidoreductases $(n=21)$, transferases $(n=15)$, lyases $(n=5)$, ligases $(n=4)$ and isomerases $(n=1)$. A further factor contributing to the large numbers of enzymes within this cluster could be the presence of numerous putative $P$. ovis allergens, many of which are homologues of HDM allergens and several of which show protease activity [55]. Analysis of abundantly-expressed genes in each individual life-cycle stage (Additional file 3) demonstrated that the cluster of 14 genes abundantly expressed in tritonymphs included a number of allergens, notably two copies of the major $P$. ovis allergen Pso o 1 (psovi14g10410 \& psovi14g10420) a homologue of the HDM allergen Der p 1, which showed expression across all life-cycle stages but with significantly $(p \leq 0.05)$ higher expression in tritonymphs [56]. In addition, the cluster contained both copies (psovi17g08010 \& psovi88g00180) of a Group 2 (Der p 2) allergen homologue (Pso o 2), which is a potential functional mimic of the TLR4 accessory protein MD-2 and may play a role in host immune activation [57] and is also used as a diagnostic 
antigen for the detection of sheep scab [58]. The same cluster also contained a Group 21 (Der p 21) allergen homologue, termed Pso o 21, which has been shown to trigger IL-8 production in airway epithelial cells through a TLR2-dependent mechanism [59] and a Group 14 (Der f 14 or M-177) apolipophorin-like allergen homologue, termed Pso o 14, characterised as a large lipid binding protein with IgE-binding and cytokine-inducing capacities [60]. Insect apolipophorins have also been demonstrated to have a role in pattern recognition as part of the insect innate immune response to fungal beta-1,3-glucan [61]. Other putative allergen genes enriched within the tritonymph cluster included some of the most abundant $P$. ovis allergens, i.e. Pso o 7, 8 and 13, along with Pso o 18, 30, 34 and 36. A further group of genes $(n=12)$ enriched in the tritonymph cluster belong to an as yet functionallyuncharacterised group of senescence-associated proteins from the two-spotted spider mite, T. urticae [20]. Another group of five tritonymph-enriched genes is co-located on a single scaffold of the $P$. ovis genome (psovi22g03270, psovi22g03310, psovi22g03330, psovi22g03320, psovi22g03340) indicating a potential shared expression and function profile. These genes showed high levels of expression in the tritonymphs but no known homologues were found from the BLAST searches, indicating that these may be unique $P$. ovis genes.

\section{Assessment of the most abundantly expressed genes for each life-cycle stage}

For each of the $P$. ovis life-cycle stages we identified the top 100 most abundantly expressed genes (i.e. highest TPM value). To assess the expression of these genes across the different life-cycle stages we used a five-way Venn/Euler diagram to examine their expression across $P$. ovis life-cycle stages (Fig. 6). The IDs and annotations of the genes attributed to each arm of the Venn diagram are detailed in Additional file 3. As can be seen in Fig. 6, a number of the most abundantly expressed genes demonstrated stage-enriched expression, for example 43 genes were enriched in females, 21 in males, 14 in tritonymphs, 11 in larvae and 6 in protonymphs. Conversely, 37 of the most abundantly expressed genes were conserved across stages (Fig. 6). Of these conserved abundant genes many are involved in the formation and contraction of muscle tissues (i.e. actin, tropomyosin, troponin, arginine kinase, muscle LIM protein 1 and smoothelin) or in glycolysis and energy metabolism (glyceraldehyde-3-phosphate dehydrogenase, fructosebisphosphate aldolase, cytochrome c oxidase subunits II and III, ATP synthase F0 subunit 6 and ADP/ATP translocase) supporting the central importance of these key biological processes across all $P$. ovis life-cycle stages. Ten genes were conserved between juvenile stages

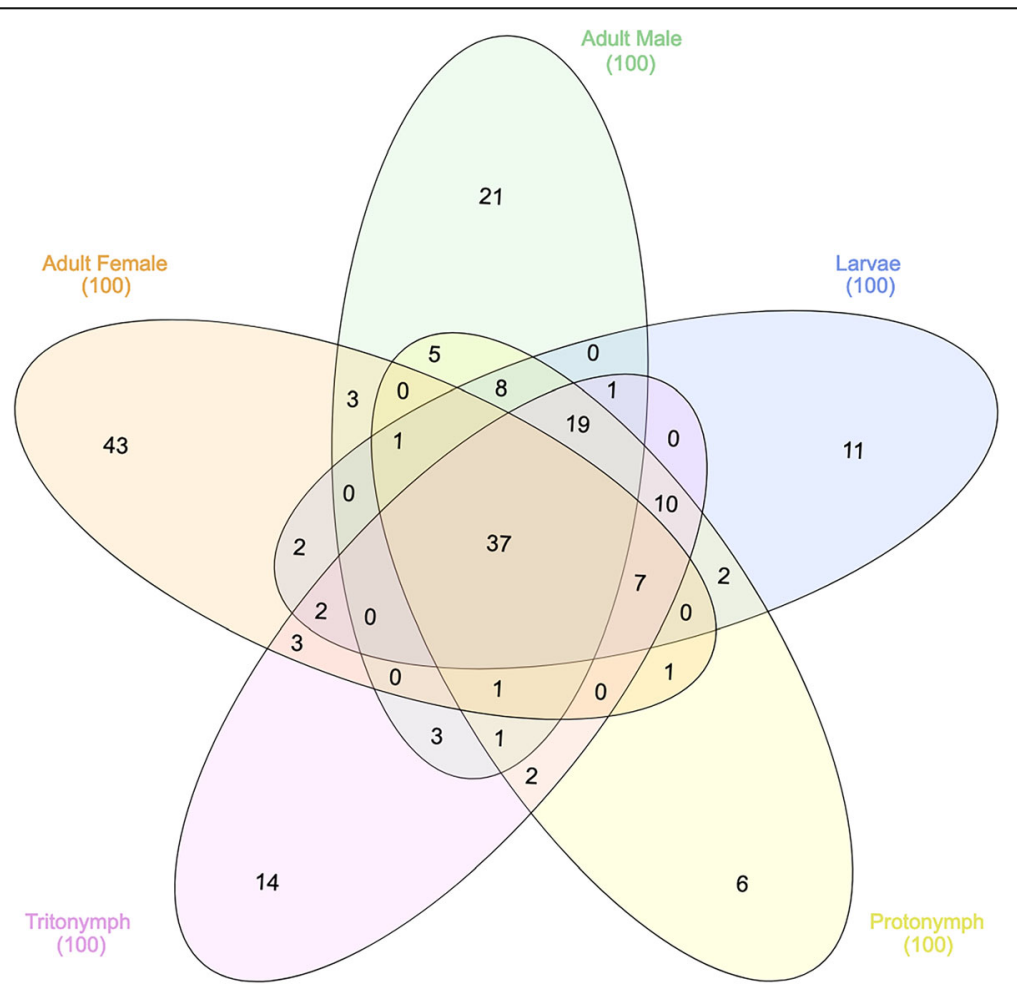

Fig. 6 Assessment of the most abundantly expressed genes for each life-cycle stage. Five-way Venn/Euler diagram highlighting the pattern of unique and shared expression of the top 100 most abundantly expressed genes from each $P$. ovis life-cycle stage 
(larvae, protonymphs and tritonymphs) including a muclass glutathione-S-transferase (GST) or Group 8 HDM allergen homologue.

Stage-specific expression of known $P$. ovis allergen genes Homologues of a number of well-characterised allergens have been identified in $P$. ovis and many of these have been shown to elicit either pro-inflammatory, or allergic, type responses in the host and are implicated in pathogenesis of sheep scab $[12,56,62]$. We sought to investigate the abundance of the $P$. ovis allergens across life-cycle stages, therefore elucidating the potential role of each stage in the elicitation of host allergic responses. To do this we examined the expression levels of the P. ovis homologues of each of the 33 HDM (D. pteronyssinus/D. farinae) allergens currently characterised by the WHO/International Union of Immunological Societies (IUIS) across $P$. ovis life cycle stages [63, 64]. Psoroptes ovis allergen homologues were identified for 31 of the 33 allergen classes, with just 2 classes (Der p 17 and Der p 35 (both uncharacterised allergens)) not identified in the $P$. ovis genome [65]. The relative expression of the 31 allergen homologues was analysed by hierarchical clustering and revealed unique clusters of stage-specific allergen expression (Fig. 7a). Of these, one allergen (Pso o 3 (Psovi81g00190)) was expressed at very low levels (TPM $\leq 1)$ across all lifecycle stages. This gene encodes a trypsin-like serine protease and previous studies, which biochemically assessed the proteolytic enzyme profiles of mixed stage $P$. ovis extracts [67] against polypeptide and peptide substrates found no evidence of serine proteinase activity [68]. The previous failure to demonstrate serine protease activity in $P$. ovis may be related to the very low levels of expression of Pso o 3 , however additional serine protease-encoding transcripts were expressed in the current analysis, e.g. Pso o 6 (chymotrypsin-like serine protease) and Pso o 9 (collagenase-trypsin-like serine protease) albeit at low levels (Pso o 6: TPM $\leq 7$, Pso o 9: TPM $\leq 30$, Fig. 7a). The most highly expressed allergens included the major mite allergens Pso o 1 (a cysteine protease, mean TPM across lifecycle stages $=965)$, Pso o $2(\mathrm{MD}-2 /$ lipid-binding protein, mean TPM = 3309), Pso o 10 (tropomyosin, mean $\mathrm{TPM}=2658$ ), Pso o 11 (paramyosin, mean $\mathrm{TPM}=742$ ), Pso o 14 (vitellogenin-apoplipophorin, mean TPM =641), Pso o 20 (arginine kinase, mean TPM =923), Pso o 26 (myosin light chain-like, mean TPM =1163) and Pso o 30 (ferritin, mean TPM = 889). As shown in Fig. 7a, a number of $P$. ovis allergen homologues clustered together based on their expression across life cycle stages. For example, Pso o 14, 27, 28, 29, 32 \& 33 showed higher levels of expression in female mites than in any other stage; whilst Pso o $1,2,7,8,13,21,30,34$ \& 36 showed highest expression in tritonymphs. Pso o 14 (vitellogenin) is a major mite allergen and the precursor for vitellin, which acts as a source of nutrients for the developing mite egg, as such elevated levels of this gene within female mites is to be expected [69-71]. Although multiple copies of genes encoding Pso o 27 were identified in $P$. ovis, one transcript in particular showed significantly $(p=<0.05)$ higher levels of expression in female mites (psovi22g04610, TPM = 15,000) than in other stages. Serpins have been implicated in arthropod development and reproduction [72] and may influence host-pathogen interactions through immunosuppression and potential roles in innate immunity, with serpins identified in the saliva of blood-feeding ticks [73-75]. In $D$. melanogaster, a Serpin-27A has been shown to inhibit the Easter protease, a step that is essential for the control of dorsal-ventral pattern formation in the developing embryo [76]. The near-exclusive expression of psovi22g04610 in adult female $P$. ovis mites, may suggest a potential role for this gene in mite embryogenesis. Interestingly, the expression of the major $P$. ovis mite allergens (Pso o 1, 2, 7, 8, $13,18,21,25,30,34 \& 36)$ was highest in tritonymphs; these and other allergens (Pso o, 14, 23 \& 27) were also found to be upregulated in mixed-stage, "fed" P. ovis mites (Fig. 7b) and may indicate that tritonymphs are the major feeding stage of $P$. ovis; potentially as part of an effort to build energy stores prior to adulthood and sexual maturation. It should be noted that protonymphs enter a stage of lethargy for up to $36 \mathrm{~h}$ prior to moulting to the tritonymph stage [77] and therefore following this moult they must acquire further nutrients before copulation, which occurs soon afterwards. More importantly the female tritonymphs moult to the adult stage just 2 days after the commencement of copulation and begin to lay eggs just 1 day later, perhaps explaining the potential increased expression of feeding related genes in the tritonymphs [77].

Another cluster of $P$. ovis allergen homologues contained genes related to actin-binding and muscle contraction/motility, i.e. Pso o 10 (tropomyosin), 11 (paramyosin), 16 (gelsolin), 20 (arginine kinase), 26 (myosin light chain) \& 31 (cofilin) the expression levels of which were highest in adult male mites and protonymphs. The fact that these genes are involved in muscle contraction and muscle motility suggests that adult males and protonymphs may be the more motile stages of $P$. ovis. This is further supported by the increased expression of Pso o 20 (arginine kinase (AK) and a homologue of the HDM allergen Der $f$ 20 [78]) in the same cluster. AK is a phosphotransferase found in a wide variety of invertebrate species, which is especially abundant in muscle tissues, where it serves a function analogous to that of creatine kinase in vertebrates $[79,80]$. The $P$. ovis genes attributed to each allergen class are shown in Additional file 4.

We identified four copies of the Group 1 cysteine protease allergen (Der p 1) homologue Pso o 1 in the P. ovis genome. These genes are co-located within the same scaffold and may represent a multi-gene family. 
A

B
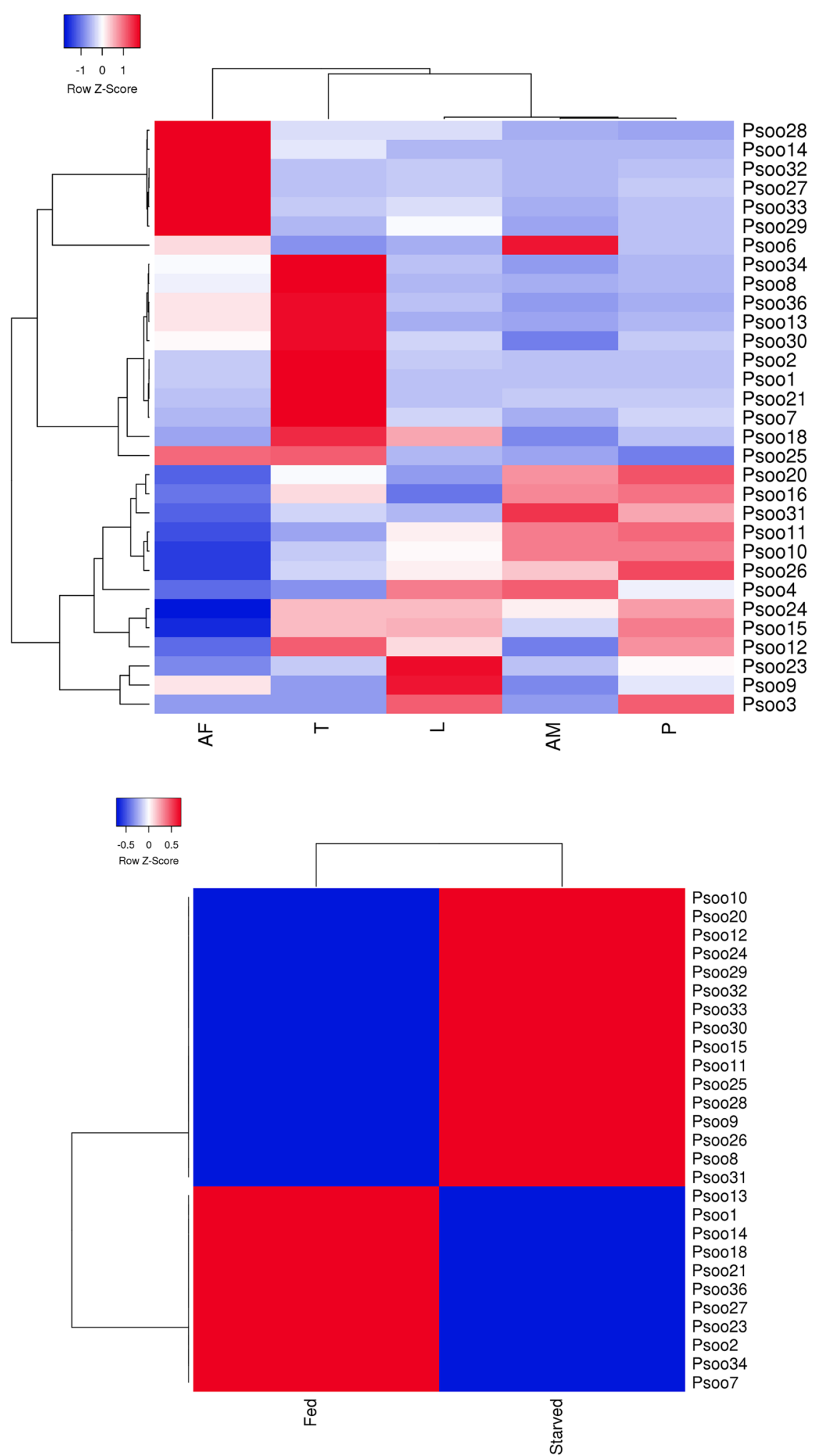

Fig. 7 (See legend on next page.) 
(See figure on previous page.)

Fig. 7 Heatmaps showing relative expression of 31 characterised $P$. ovis homologous allergen genes. a Stage-specific expression of $P$. ovis allergens: Larvae (L), Protonymph (P), Tritonymph (T), Adult Female (AF), Adult Male (AM). b Allergen expression between "fed" and "starved" $P$. ovis mites. Each allergen is named according to the World Health Organization and International Union of Immunological Societies (WHO/IUIS) allergen nomenclature, i.e. Pso o 1 for P. ovis Group 1 allergen. Where multiple copies of allergen genes were identified, mean expression (TPM) data was used. Relative expression shown as average TPM across three replicates/life-cycle stage/condition. Heatmaps were generated using the open source package Heatmapper [66] and Hierarchical clustering was performed using the average or unweighted pair-group method based on Pearson distance measurements

Expression data showed that three of the four copies of the gene were expressed at relatively high levels (psovi14g10400-10,420 (Average TPM =966)) whilst the remaining copy, psovi14g10430 was expressed at a very low level $(\mathrm{TPM}=16)$. To further investigate this potential multi-gene family, we performed a multiple sequence alignment of the four Pso o 1 genes with the house dust mite homologues Der p 1 (D. pteronyssinus) and Der f 1 (D. farinae) (Fig. 8). The alignment demonstrates the strong similarity between Der $\mathrm{p} / \mathrm{f} 1$ and Pso $o 1$ and also highlights the conservation of the key cysteine residues and the cysteine protease catalytic triad (QHN) as previously characterised for Der p/f 1 [82]. As detailed above Pso o 1 was most highly expressed at the tritonymph stage and was also upregulated $(\sim 4$-fold $)$ in "fed" versus "starved" $P$. ovis mites. Amongst the 870 genes identified using edgeR analysis of differential gene expression between "fed" and "starved" $P$. ovis mites (see below) as being upregulated in "fed" mites, we identified 94 genes representing known allergens, including representatives of all but seven (Pso o 3, 6, 29, 31, 32, 33 and 34) of the WHO/IUIS allergen groups identified in $P$. ovis. This group included the main $P$. ovis allergens, i.e. Pso o $1,2,4,7,8,9,10,11,12,13,14,15,16,18$, $20,21,23,24,25,26,27,28,30$ and 36; indicating that many allergen genes are upregulated during feeding activity, and as noted earlier, that much of this expression may be attributed to the tritonymphs. Genes representing just two allergen groups were identified in the downregulated genes in fed mites, Pso o 29 (peptidyl-prolyl cis-trans isomerase or cyclophilin) and Pso o 33 (alpha-tubulin). Interestingly, our previous assessment of feeding-related expression based on a novel but limited cDNA microarray also showed down-regulation of a $P$. ovis tubulin transcript in "fed" mites [16]. A similar pattern was also observed in two previous assessments of feeding related expression in P. ovis: Burgess et al. [16] identified o 1, Pso o 2, Pso o 14 and Pso o 21 as upregulated in "fed" mites, with no allergens being downregulated and McNair et al. [15] identified the up-regulation of Pso o 1, Pso o 27, Pso o 13 and Pso o 21 in "fed" $P$. ovis. It should be noted that both previous studies relied on the interrogation of a limited number of transcripts and were also hampered by the relatively poor levels of annotation available $[15,16]$.

\section{Pairwise determination of differentially expressed genes}

Pairwise analysis of differential gene expression between individual life-cycle stages and between "fed" and "starved" $P$. ovis mites was performed with edgeR (Version 3.7 [83]) based on a fold change cut-off $\geq \pm 2$ and an FDR corrected $p$-value of $\leq 0.05$ (Table 2). The fully annotated lists of differentially expressed genes identified from each of the pairwise life-cycle stage comparisons are available in Additional file 5.

\section{Feeding related gene expression in $P$. ovis}

edgeR analysis of differential gene expression between "fed" and "starved" P. ovis mites identified 1227 significantly differentially expressed genes, based on a fold change cut-off $\geq \pm 2$ and an FDR-corrected p-value of $\leq 0.05$ (Table 2). Of these the majority of genes $(n=870)$ were upregulated in the "fed" mite population, whilst 357 genes were upregulated in the "starved" mite population (Additional file 5). A six-way Venn/Euler diagram analysis of gene expression across the $P$. ovis developmental stages (Larvae, Protonymph, Tritonymph, Adult Females and Adult Males with genes significantly upregulated in "fed" mites (Fig. 9) demonstrated that $46 \%$ $(n=242)$ of the tritonymph specific transcripts were also upregulated in the "fed" mite population. In contrast just $7.5 \%$ of adult male $(n=67), 2.5 \%$ of adult female transcripts $(n=76), 5.4 \%$ of larval transcripts $(n=6)$ and $28 \%$ of protonymph transcripts $(n=62)$ were found to be upregulated in "fed" mites; thus, further supporting the potential role of tritonymphs as the major feeding stage of P. ovis.

Of the top upregulated genes in "fed" P. ovis mites, 12 belong to an uncharacterised group of senescence-associated proteins with fold change values ranging between 65 to > 800 -fold in "fed" mites, with the same transcripts also enriched in the tritonymph cluster (see above). As observed in the tritonymph-enriched gene cluster, the same group of five co-located genes (psovi22g03270, psovi22g03310, psovi22g03330, psovi22g03320, psovi22g03340) for which no known homologues were identified, were also found to 


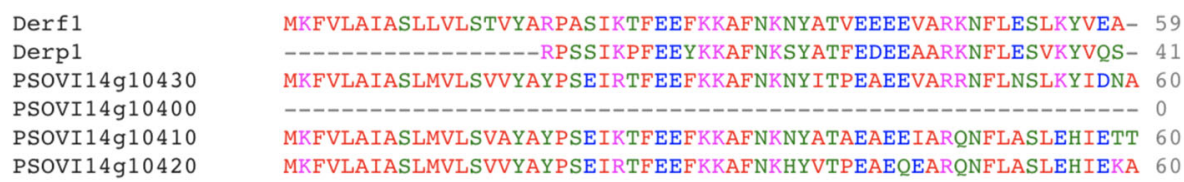

NKGAINHLSDLSLDEFKNRYLMSAEAFEOLKTOFDLNAETSACRINSVNVPSELDLRSLR 119 NGGAINHLSDLSLDEFKNRFLMSAEAFEHLKTOFDLNAETNACSING-NAPAEIDLROMR 100 GQGRINHLSDLSLEEFKKYYMMSDRAYEQLKQQFDINAGVSH CKTPQANYPAAFDLRALG 120 --_-------_----MMSDMAFEALKOEFDLNAGHSA COIPOTRYPGEMDLRAMR 40 GKGRINHLSDLSLEEFKRQYLMSDSAYEQLKQQFDLNAGVQY CNVPRVNLPHEIDLRAMG 120 GKGRINQF SDMSLEEFKNQYLMSDQAYEALKKEFDLDAGAQACQIGAVNIPNEIDLRALG 120 $: * * * * * *: * *: * *, * \quad *: * * *:$

TVTPIRMOGGCGSCNAFSGVAATESAYLAYMNSLDLSEQKLVDCASOHGCHGDTIPRGI 179 TVTPIRMOGGCGSCWAFSGVAATESAYLAYH NSLDLAEOELVDCASOHGCHGDTIPRGI 160 TVPKIKDOGEC GSCWAFSTLACVESTYLASA NSLDLSEQELVDCAAENGCDGDTVINGM 180 HLTRIKD EA C GS CWAFS SVATVESTYLSF N VSLDLSEQELVDCASOHGCDGDTIPNGF 100 HVTKIKN PA C GS CNAFS SVATVESTYLAY N VSLDLSEQELVDCASQHGCDGDTMPHGL 180 YVTKIKN OVACGSCWAFS GVATVESNYLSYDN VSLDLSEOELVDCASOHGCGGDTVLNGL 180

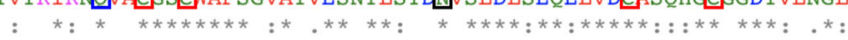

EYIOONGVVEERSYPYVAREOOCRRPNSOHYGISNYCDIYPPDVKOIREALTOTHTAIAV 239 EYIQHNGVVQESYYRYVAREQS CRRPAQRFGISNY CIYPPNANKIREALAQTHSAIAV 220 GYVKKNGVVDEKSYPYIDGQOK KKPNGKRTGISS F MVYPOEGGKIRKHLVGTKAAISV 240 RYLMRNGVVHERSYPYRARVGR CQKPNARRTGITNF CDITLSNGDKIRKVLASTKSAMSV 160 GYIAENGVVEERSYPYRARAGR QRVDSRRIYISD CEIYPPSSNKIRRTLAATKSAMSV 240 RYIQKNGVVEEQSYPYKAREGRCDRPNAKRYGIKDICDIYPPNGDKIRTYLATKQAALSV 240

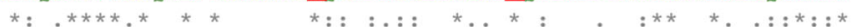

IIGIKDLRAFOHYDGRTIIOHDNGYOPNYA AVNIVGYGSTOGVDYWIVHNSWDTTWGDSG 299 IIGIKDLDAFRHYDGRTIIORDNGYOPNYHAVNIVGYSNAOGVDYWIVH N SWDTNWGDNG 280 VIGIKDMDAFRHYDGKS I IMKDNGPKNNY HANIVGYGLRQGIPYWVIN NWSTTWGDQG 300 IVGIRDLDSFRHYDGRSIYQTDGGYKKNYHAINIVGYGTRQGVPYWIVHNSWSTTWGDNG 220 IIGIKDLDSFRHYDGRTVLOTDRGYNNNYHAVNIVGYSSVOGVRYWIVHN SWDTAWGDNG 300 IIGIRDLDSFRHYDGRTILQSDNGGKRNH HAINIVGYGSKQGVRYWI IN NSWTTWGDKG 300 $:: * *: *:: *: * * *::: * *: * * * *: * * * *, * *: * *:: * * * * * * * * * *$

YGYFQAGNNLMMIEQYPYVVIM YGYFAANIDLMMIEEYPYVVII YGYMLADENFMGIETSPLVVNL YGYFIADKNFMGIEQYPYVVMI YGYFIADRNFMGIESYPYVAIL YGYFVADKNLMGIEKFPLAAMI $* * *: *,: * * * * \ldots$,

Fig. 8 Multiple sequence alignment of Group 1 allergens from HDM (Der $p 1$ and Der $f$ 1) and $P$. ovis (Pso o 1). Sequence alignment generated with EBI Clustal Omega tool [81]. Pso o 1: psovi14g10400-10,430. Der f 1 (Uniprot ID: A1YW12), Der p 1 (Uniprot ID: Q3HWZ5). Red boxes mark conserved cysteine residues $(\times 7)$, Blue boxes mark catalytic residues $(\mathrm{Q}, \mathrm{H}, \mathrm{N})$ as identified in [82]. Black box marks potential Pso o 1 N-glycosylation site

be upregulated in the "fed" mite population with fold change values ranging from 45 to 92 -fold higher in "fed" mites. A number of genes encoding putative large lipid transfer proteins were also highly upregulated in "fed" mites, including vitellogenin (psovi09g01710), apolipophorin (psovi73g00070), a microsomal triglyceride transfer protein (psovi05g02390) and a homologue of the high molecular weight allergen M177 from HDMs (psovi73g00570) which may play a role in the transport of minerals, amino acids, lipids, and other nutrients to the developing oocyte [84] with both vitellogenin and apolipophorin having been previously shown to be upregulated in "fed" P. ovis mites [16]. A number of the $P$. ovis allergens identified as being upregulated in the "fed" mites represent enzymes and may play a role in mite feeding/digestive activities, for example: Pso o 1 (cysteine protease), Pso o 4 (amylase), Pso o 9 (serine protease) and cathepsins L and B. A number of genes potentially involved in xenobiotic metabolism were also upregulated in the "fed" mite population, including seven cytochrome P450 monooxygenases (CYPs), six glutathione-S-transferases (GSTs - mu, kappa and deltaclasses) and six carboxyl/choline esterases (CCEs). The upregulation of genes involved in detoxification in feeding mites is likely to be related to increased digestive activity and subsequent higher exposure to toxic compounds from the host. We performed a GO analysis of sequences found to be significantly upregulated in the "fed" P. ovis population and, of the 870 upregulated genes, significant BLAST hits and/or GO terms were assigned to 775 genes (89\%) with multiple $\mathrm{GO}$ terms being assigned to many genes. Figure 10 shows the distribution of sequences per GO term across multiple classification levels, presented as pie-charts showing GO term distributions for Biological Process, Molecular Function and Cellular Component. 
Table 2 Numbers of differentially expressed genes (DEGs) between P. ovis life-cycle stages and between "fed" and "starved" mites

\begin{tabular}{llll}
\hline Comparison $^{\text {a }}$ & Number of DEGs & Upregulated genes & Downregulated genes \\
\hline P vs. T & 2018 & 962 & 1056 \\
P vs. L & 277 & 112 & 165 \\
L vs. T & 2734 & 1328 & 1406 \\
AM vs. T & 2908 & 1748 & 1160 \\
AM vs. P & 1590 & 1167 & 423 \\
AM vs. L & 2162 & 1451 & 711 \\
AF vs. T & 4585 & 2143 & 2442 \\
AF vs. P & 5286 & 2571 & 2715 \\
AF vs. L & 5444 & 2734 & 2710 \\
AF vs. AM & 5433 & 2376 & 3057 \\
"Fed" vs. "Starved" & 1227 & 870 & 357
\end{tabular}

$A F$ adult females, $A M$ adult males, $L$ larvae, $P$ protonymph, $T$ tritonymph

${ }^{\mathrm{a}}$ Direction of fold change is relative to the first stage, or condition for each comparison

The upregulated transcripts were further explored by mapping them to the Kyoto Encyclopedia of Genes and Genomes (KEGG) pathway database within Blast2GO; this resulted in the mapping of 213 enzyme sequences across 92 KEGG pathways. The most over-represented enzyme class was for hydrolases (42.7\%) followed by oxidoreductases $(22.5 \%)$, transferases (22\%), lyases (6.6\%), ligases $(3.8 \%)$ and isomerases (2.3\%). We then used Blast2GO to further investigate the enzyme code distributions between the genes upregulated in "fed" mites and those downregulated in "fed" mites. As expected more enzyme-coding genes were found in the "fed" mite population, however, these increases were most profound amongst the oxidoreductase ("starved" $n=9$, "fed" $n=45$ ) transferase ("starved" $n=16$, "fed" $n=43$ ) and hydrolase ("starved" $n=23$, "fed" $n=61$ ) enzyme classes. For hydrolases more sequences were found amongst the esterase ("starved" $\mathrm{n}=2$, "fed" $n=15)$ glycosylase ("starved" $n=0$, "fed" $n=9$ ) and peptidase families ("starved" $n=2$, "fed" $n=15$ ), including a cathepsin B (psovi284g00790). For transferases the main difference was observed amongst the glycosyltransferases ("starved" $n=1$, "fed" $n=8$ ) whilst the "fed" mites also showed an increase in the number of glutathione-Stransferases (GSTs) ("starved" $n=0$, "fed" $n=3$ ) a number of which are known allergens and may play a role in xenobiotic metabolism [85]. For oxidoreductases the main differences were observed in peroxidases ("starved" $n=0$, "fed" $n=6$ ) superoxide dismutases ("starved" $n=0$, "fed" $n=2$ ) indicating a potential response to free radicals produced by the host.

\section{Genes differentially expressed between $P$. ovis life-cycle stages}

Differential expression analysis revealed a total of 7825 genes that showed differential expression between one or more of the selected $P$. ovis life-cycle stages. We focused on the major transition phases between $P$. ovis life-cycle stages with the following comparisons being highlighted below: Adult female (AF) vs. adult male (AM), Adult female (AF) vs. tritonymph (T), Adult male (AM) vs. tritonymph (T), Larvae (L) vs. protonymph (P) and Protonymph $(\mathrm{P})$ vs. tritonymph $(\mathrm{T})$.

\section{Adult female (AF) vs. adult male (AM)}

In total, 5433 genes were found to be differentially expressed between AF and AM stages. Of these 2376 were upregulated in the AF mites with 3057 being downregulated. The gene with the highest degree of differential expression between AF and AM mites was a homologue of a skin secretory protein, xP2-like from Xenopus laevis (psovi14g01150) which showed a > 900-fold increase in expression in AF mites (Average $\mathrm{TPM}=5222(\mathrm{AF})$ and $5(\mathrm{AM})$ ). Another differentially expressed gene was a Der p 27 homologue, Pso o 27 (psovi22g04610) with a $>900$-fold increase in expression in AF mites (Average TPM $=15,003(\mathrm{AF}$ ) and 16 (AM)). Genes upregulated in the AM population in a sex-specific manner were the $P$. ovis allergens Pso o 10 (tropomyosin), Pso o 11 (paramyosin), Pso o 20 (arginine kinase - psovi292g02430), Pso o 26 (myosin alkali light chain), Pso o 31 (cofilin - psovi43g01240) and a P. ovis paxillin homologue (psovi63g00070) and 17 genes characterised as encoding putative secreted salivary gland peptides. Two such peptides were upregulated in the AF mite population.

\section{Adult female (AF) vs. tritonymph (T)}

The comparison between adult female and tritonymphs is important as it may inform upon differences in gene expression between the ovigerous female stage and the final nymphal stage before the final moult into an adult. 


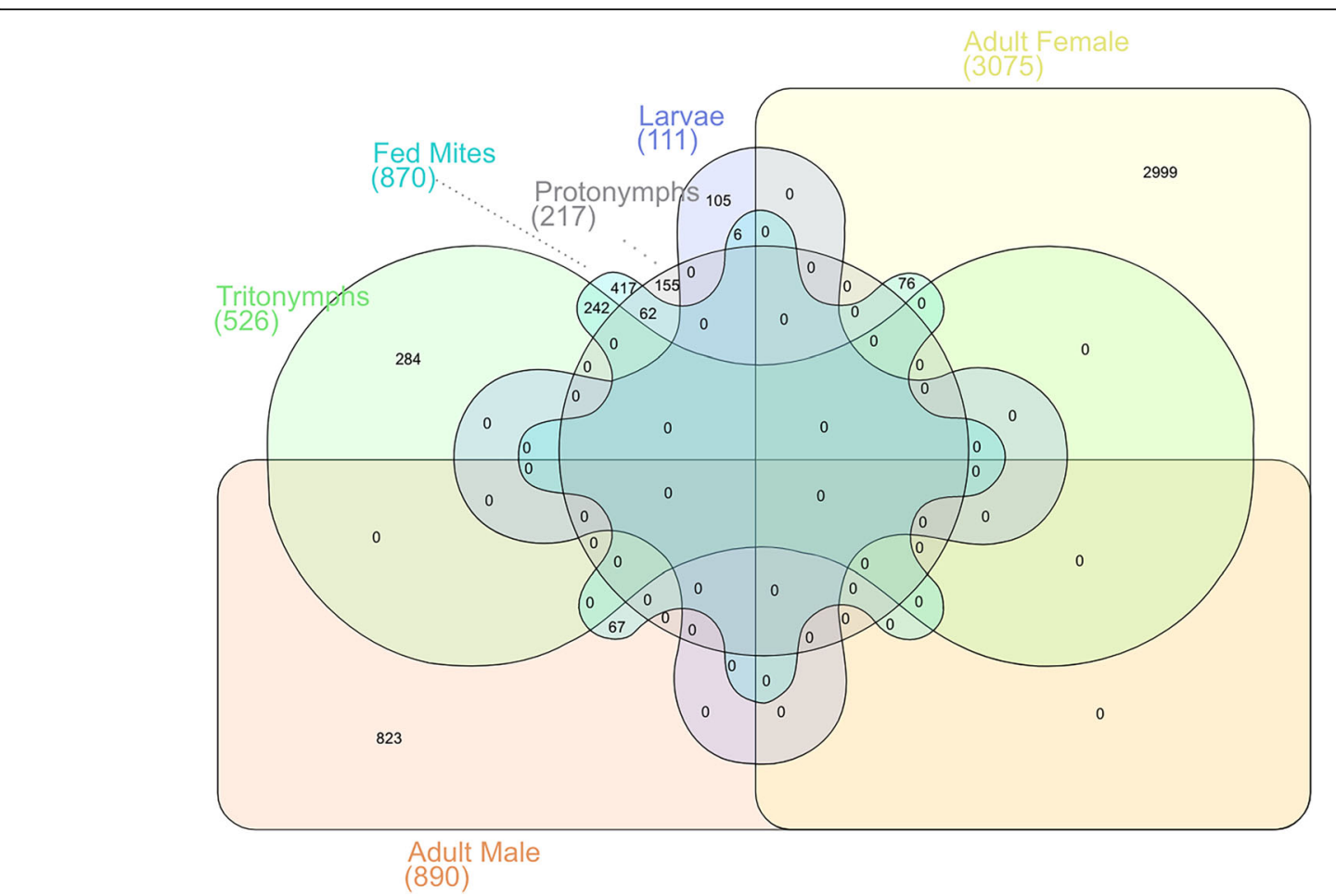

Fig. 9 The P. ovis tritonymph stage is most closely associated with "fed" mite transcriptional changes. Six-way Venn/Euler diagram demonstrating gene conservation between $P$. ovis life-cycle stages. Each arm consists of the genes from the stage-specific expression clusters shown in Table 1. (Larvae, Protonymph, Tritonymph, Adult Females and Adult Males and genes whose expression was significantly upregulated in "fed" P. ovis mites ("Fed" Mites) compared to "starved" mites)

As such the tritonymph population represents the final phase of immature mites, which will go on to develop into either adult males or females. We identified 4585 genes that were differentially expressed between AF and $\mathrm{T}$ stages. Of these 2143 were upregulated in the AF mites with 2442 downregulated with respect to the tritonymphs. The AF population showed higher levels of expression of transcripts encoding the skin secretory protein $\mathrm{xP2}$-like protein (635-fold higher in AF vs. T); Pso o27 (375-fold higher in AF vs. T); vitellogenin ( 350-fold up in AF vs. T); vitellogenin receptor ( $\sim 60$-fold up in AF); Pso o 14 (147-fold up in AF) and an ABCA1 lipid exporter protein gene (72-fold up in AF). A further group of 28 histone-related genes, including $P$. ovis homologues of histone $\mathrm{H} 1 \mathrm{~B}(n=2), \mathrm{H} 2 \mathrm{~A}(n=2), \mathrm{H} 2 \mathrm{~B}(n=3), \mathrm{H} 3, \mathrm{H} 4$ $(n=2)$, a putative histone chaperone protein, histone deacetylase $(n=2)$, histone binding protein $(n=3)$, a histone RNA hairpin binding protein and 12 putative histone methyltransferases were all up regulated in the AF population, indicating a potential role of chromatin remodelling during the transition phase from tritonymph to adult female. Transcripts upregulated in the tritonymphs included 42 homologues of the HDM DFP2 gene, 17 putative cuticle protein genes and 17 chitin-binding protein genes. All of these were similarly highly expressed in the tritonymph-enriched cluster described above, indicating the specific role that these genes may play in the development of this stage. Many of the known and putative $P$. ovis allergen genes were also highly expressed in tritonymphs, the differential expression analysis confirmed these findings but also showed that the following antigens are often expressed at low levels in the AF mites, including: Pso o 1, 2, 7, 8, 10, 11, 13, 21, 30, 34 and 36. Two further groups of genes showing higher levels of expression in the tritonymphs compared to the AF mites were six troponin genes, including troponin-I, $\mathrm{C}$ and $\mathrm{T}$ and the uncharacterised senescence associated proteins $(n=8)$ identified in the tritonymph-enriched cluster above.

\section{Adult male (AM) vs. tritonymph (T)}

The assessment of differential expression between adult males and tritonymphs provides an opportunity to determine gene expression changes related to the sexual maturation of the male. In total, 2908 genes were found to be differentially expressed between AM and T stages. Of these 1748 were upregulated in the AM mites with 1160 being downregulated with respect to the tritonymphs. Two of the most differentially expressed genes between the AM and $\mathrm{T}$ stages were a putative $P$. ovis 


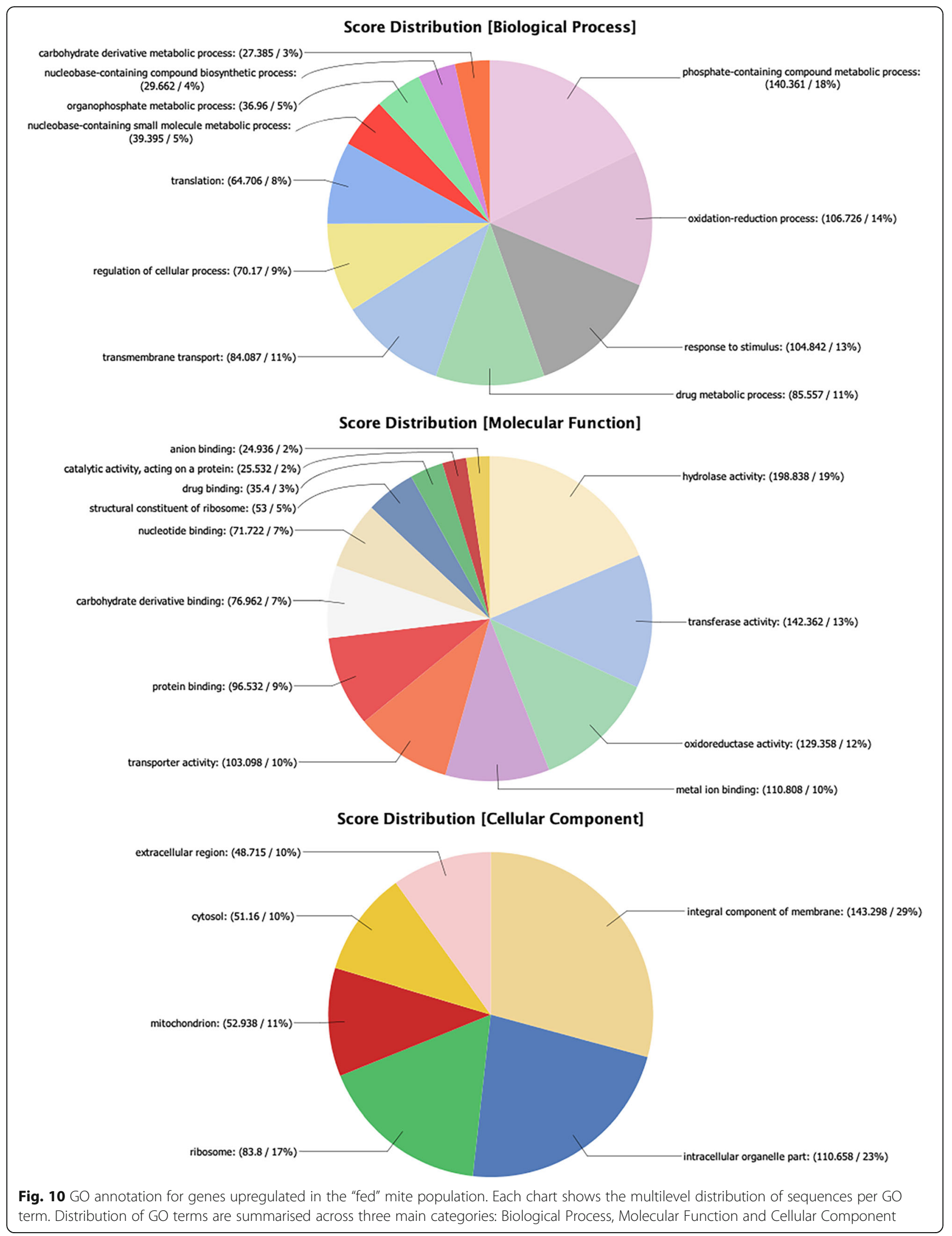




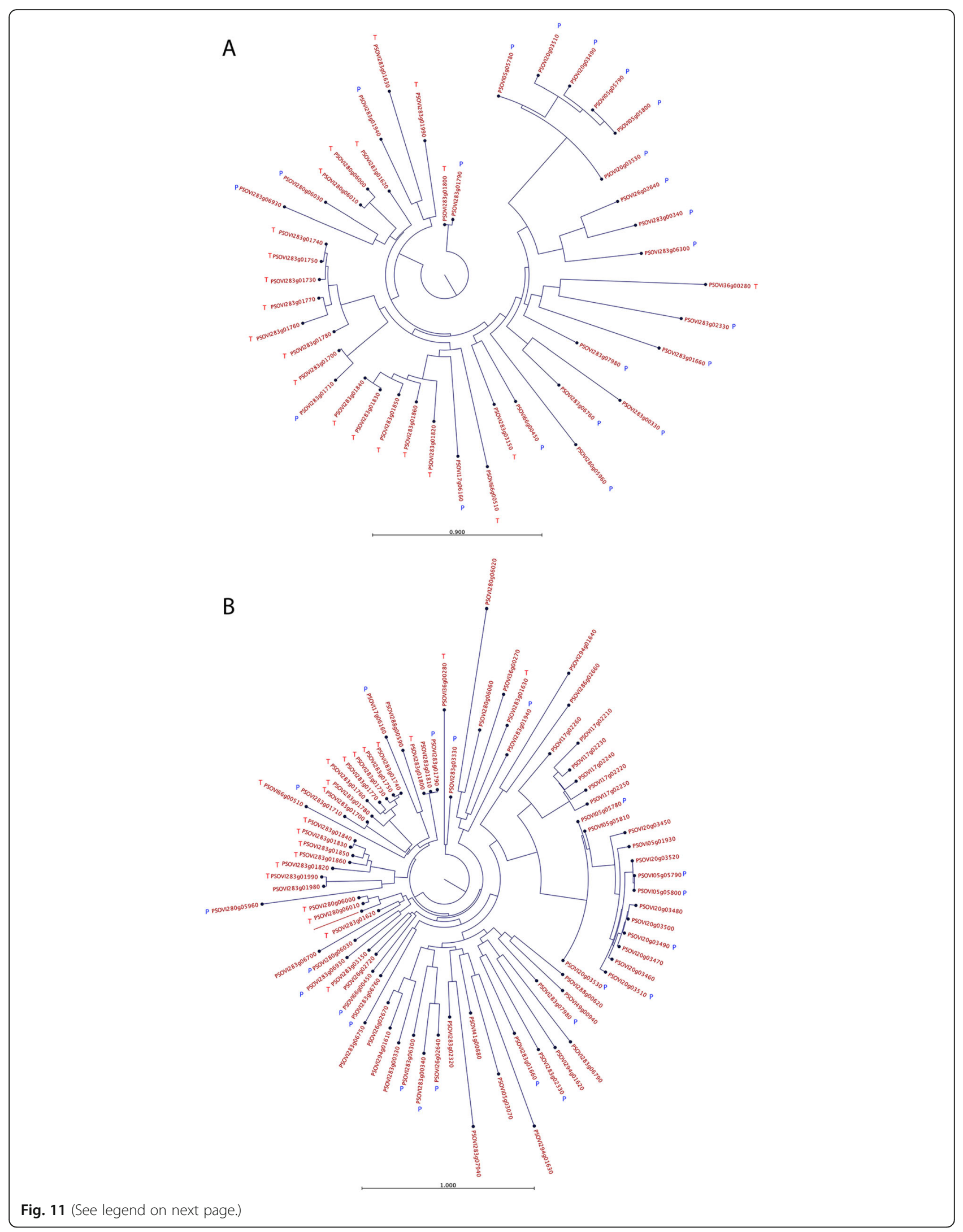


(See figure on previous page.)

Fig. 11 Phylogenetic analysis of DFP2-like proteins from P. ovis. Trees were constructed using a maximum likelihood phylogeny method with neighbour joining tree construction and Jukes-Cantor distance measure with 100 bootstraps. a DFP2-like genes differentially expressed $(n=44)$ between protonymph and tritonymph stages. b The 81 predicted P. ovis DFP2-like protein sequences from the draft $P$. ovis genome. DFP2-like genes upregulated in tritonymphs (vs. protonymphs) are highlighted with a red T; whilst those upregulated in protonymphs (vs. tritonymphs) are highlighted with a blue $P$

cystatin (psovi52g00910 (144-fold up in AM)) and two cathepsin-L-like genes (psovi283g01960 (12-fold up in AM) and psovi295g01310 (98-fold up in AM)). Seven further highly expressed genes (psovi22g04380, psovi280g06090, psovi280g02150, psovi14g05340, psovi22g04360, psovi22g04350 and psovi22g06400) in the AM population showed much lower expression in the $\mathrm{T}$ stage (ranging from 600 to 1500-fold higher in AM vs. T). A group of 13 putative testisspecific serine/threonine-protein kinases were upregulated in the adult males compared to the tritonymphs (ranging between 2 and 35 fold higher in the male mites). As with the AF vs. $\mathrm{T}$ comparison, we observed large numbers of differentially expressed HDM, DFP2-like transcripts between the adult male and tritonymphs. However, the pattern here was different with 14 DFP2-like transcripts being upregulated in the AM mites compared to the tritonymphs, albeit all but one of these (psovi283g01710) showing relatively low levels of expression in the AM population. In contrast, we identified 36 DFP2-like transcripts upregulated in the tritonymphs and many of these were expressed at very high levels ( $>100,000$ mean TPM). Cuticle-associated protein genes $(n=14)$ and chitin-binding proteins $(n=12)$ were also significantly upregulated in the tritonymphs compared to the adult males, with just one cuticle protein and three chitin-binding factors up regulated in the AM population. In terms of allergen expression, the majority of allergens were again upregulated in the tritonymphs compared to the adult males, however, there were a few exceptions, with Pso o 10 (tropomyosin), Pso o 11 (paramyosin), Pso o 20 (arginine kinase), Pso o 26 (myosin alkali light chain) \& Pso o 31 (cofilin) all upregulated in the AM population and all with potential roles in muscle development and contraction.

\section{Larvae (L) vs. protonymph (P)}

We identified 277 genes differentially expressed between $\mathrm{L}$ and $\mathrm{P}$ stages. Of these 165 were upregulated in the protonymphs with 112 being downregulated with respect to the larvae. Of the 165 upregulated genes in the protonymphs, 29 (18\%) showed homology to HDM, DFP2like factors, many of which showed very high levels of expression in the protonymphs with low levels of expression in the larvae. In addition, cuticle-associated factors $(n=15)$ were also significantly upregulated in the protonymphs with just one cuticle-like protein upregulated in the larvae. This seems to indicate that the P. ovis DFP2- like genes and the high levels of cuticle-like protein gene expression are more-associated with the nymphal stages, rather than the larval stage.

\section{Protonymph $(\mathrm{P})$ vs. tritonymph $(\mathrm{T})$}

In total, 2018 genes were found to be differentially expressed between $\mathrm{P}$ and $\mathrm{T}$ stages. Of these 962 were upregulated in the protonymphs with 1056 being downregulated with respect to the tritonymphs. Of these 44 differentially expressed transcripts relate to HDM, DFP2-like genes, with 21 upregulated in the tritonymphs and 23 upregulated in the protonymphs; suggesting that there may be different families of DFP2-like genes, which share similar stage-specific patterns of expression. To investigate this further we generated an alignment of the predicted protein sequences for the 44 differentially expressed DFP2-like genes and also for all of the predicted $P$. ovis DFP2-like proteins identified in the genome $(n=81)$. The resulting phylogenetic trees (presented as circular phylograms) can be seen in Fig. 11. The first of these (Fig. 11a) shows the differentially expressed (protonymph vs. tritonymph) DFP2-like protein sequences, whilst Fig. 11b shows all 81 predicted DFP2-like protein sequences identified in the $P$. ovis genome. The circular phylograms clearly demonstrate clustering of the DFP2-like sequences that are specifically upregulated in the tritonymphs (labelled with a red T) and, separately, those upregulated in protonymphs (labelled with blue P), demonstrating conserved sequences in particular life-cycle stages and suggesting the potential for distinct biological functions of DFP2-like proteins in each stage. In addition, of the 21 DFP2-like genes upregulated in tritonymphs, 16 are co-located on the same scaffold (psovi283) indicating the potential for these to be coregulated or expressed.

\section{Conclusions}

This study represents the first large-scale genomic and transcriptomic analysis of sex- and stage-specific and feeding-related gene expression in a parasitic astigmatid mite. It also presents, for the first time the complete annotation of the $P$. ovis draft genome and predicted transcriptome. The analysis showed clear patterns of gene expression attributed to individual $P$. ovis life cycle stages including, for the first time, the demonstration that previously-characterised allergens may exhibit both stagespecific and feeding-related patterns of gene expression; a finding of particular importance when developing novel 
means of control, i.e. vaccination. Stage-specific allergen expression was demonstrated for a number of known $P$. ovis allergens, including the major mite allergen Pso o 1 (a homologue of the HDM allergen Der p 1). By exploiting the draft genome for $P$. ovis we were also able to show that Pso o 1 is a member of a multigene family (with four copies co-located on a single scaffold) showing high levels of expression across life-cycle stages but with increased expression in tritonymphs. The observation that tritonymph stage-enriched expression overlaps closely with feeding-related gene expression points to the tritonymphs being the main feeding stage of $P$. ovis and the identification of novel multigene families (i.e. $P$. ovis putative senescence-associated proteins) may offer future targets for control. The analysis of sex-specific expression in $P$. ovis showed that large numbers of transcripts expressed in the female mites are dedicated to the process of oogenesis, whilst in the males we observed expression of numerous genes involved in muscle development and contraction, perhaps reflecting the increased mobility of the adult males as they seek out multiple females for copulation. We identified a further novel multigene family in P. ovis, which consisted of 81 genes showing close homology to the HDM DFP2-like gene. Phylogenetic analysis of $P$. ovis DFP2-like genes revealed separate clustering of DFP2-like sequences that were specifically upregulated in protonymphs and tritonymphs, demonstrating expression of closely-related members of this family in particular $P$. ovis stages and suggesting distinct biological function amongst the DFP2-like proteins. By building on our recent publication of the $P$. ovis draft genome we have now generated the first genomic and transcriptomic atlas of gene expression in $P$. ovis. This represents a unique resource for this economically important parasite and also provides the first gene expression atlas for an astigmatid parasitic mite, which can now be exploited by the wider acarid-research community. The OrcAE platform and accompanying $P$. ovis transcriptomic atlas, is publicly accessible and represents a means by which the draft $P$. ovis genome can be further improved via a process of community-led manual curation.

\section{Methods}

\section{$P$. ovis collection and life-cycle staging}

Psoroptes ovis mites (a mixed population consisting of adults, nymphs and larval stages) were harvested from infested donor sheep maintained at the Moredun Research Institute as previously described [18]. Individual $P$. ovis mites derived from this mixed population were separated into the following life-cycle stages by staff at Fera Science Ltd.: Adult Females (AF), Adult Males (AM), Larvae (L), Protonymph (P) and Tritonymph (T). Mites from each life-cycle stage were then divided into three equal sized pools, snap frozen in liquid nitrogen and stored at $-80^{\circ} \mathrm{C}$ prior to RNA extraction.

\section{$P$. ovis collection - "fed" and "starved" mites}

The "fed" $P$. ovis mite samples $(n=3)$ were taken from the mixed population as described above, prior to staging and split into 3 pools. "Starved" $P$. ovis mites $(n=3)$ were also obtained from the mixed population but following the harvest, mites $(\sim 100 \mathrm{mg})$ were placed into a $75 \mathrm{~cm}^{2}$ vented cap cell culture flask (Corning, UK) and incubated for 4 days at $25^{\circ} \mathrm{C}$ with $80-90 \%$ relative humidity and then split into 3 pools.

\section{RNA extraction and quality control}

Total RNA was extracted from the triplicate pools for each life-cycle stage and from the "fed" and "starved" mite populations. This was achieved by homogenisation (within a pestle and mortar under liquid nitrogen) in TRIzol Reagent (Thermo Fisher Scientific Ltd., UK) according to the manufacturer's protocol. RNA samples were further purified using a Qiagen RNeasy kit, following the manufacturer's RNA clean-up protocol and on-column DNase I digestion for $15 \mathrm{~min}$ at room temperature, prior to elution into RNase free $\mathrm{dH}_{2} \mathrm{O}$. Total RNA yield was assessed by Nanodrop spectrophotometer (Nanodrop, Thermo Scientific Ltd., UK) and RNA quality was determined by Agilent Bioanalyser (Agilent, UK) using the RNA Nano-chip kit (Agilent, UK).

\section{Library preparation and transcriptome sequencing}

TruSeq RNA-seq libraries (Illumina, San Diego, USA) were prepared from the $15 P$. ovis life-cycle stage RNA samples (in triplicate for each of the life-cycle stages (biological replicates)) and for the six P. ovis samples for the "fed" vs. "starved" comparison (3 pools of each) according to the manufacturer's instructions. Sequencing was performed on the Illumina HiSeq 2000 platform with version 3 chemistry (Ilumina, USA) by the Gene Pool Next Generation Sequencing Service at the University of Edinburgh with 50 base single-end sequencing for the $P$. ovis life-cycle stages and 50 base paired-end sequencing for the "fed" vs "starved" comparison.

\section{Bioinformatic analysis}

Base calls were made using the Illumina CASAVA 1.8 pipeline. Post-sequencing, read quality of raw FASTQ files was checked with FastQC v0.10.154. The CLC Genomics Workbench (Version 12, Qiagen Ltd) was used for adapter, quality, ambiguity, and length trimming. For alignment of the read data, we employed the draft genome assembly for $P$. ovis which is a $\sim 63.2-\mathrm{Mb}$ genome containing 12,041 predicted protein-coding genes [15]. Pseudo alignment of the read data to the $P$. ovis genome (Accession ID: PQWQ01000000) [18] was performed in Kallisto (Version 0.44.0 [26]. Kallisto 
generated read counts (transcripts per million (TPM)) for all RNA-seq samples, which were used as input for the network clustering within the Graphia Professional package (Version 2.0, Kajeka, Edinburgh, UK) [29, 86]. Functional annotation of the $P$. ovis genome and specific-gene clusters was performed within the Blast2GO package (Version 5) [87]. Venn/Euler diagram analysis was performed using InteractiVenn [88]. Heatmaps were generated using the open source package Heatmapper [66].

\section{Determination of differentially expressed genes}

The statistical package edgeR (Version 3.7) within the $R$ software suite (Version 3.1) was used to analyse the RNA-seq (Illumina Hi-Seq) data and to identify transcripts significantly differentially expressed between $P$. ovis life-cycle stages and between "fed" and "starved" mites [83, 89, 90]. Read count data, as TPM from Kallisto, for each replicate of each stage, or condition, were used as the input data for the differential expression analysis [90]. As a pre-filtering step we also removed features without a TPM value of $>1$ in each of the 3 replicates per life-cycle stage or condition. Significantly differentially expressed transcripts were classified as those having a fold change $\geq \pm 2.0$ between each of the pairwise comparisons of $P$. ovis life-cycle stages $(n=10)$ or between "fed" and "starved" mites and a False Discovery Rate (FDR) corrected $p$-value of $\leq 0.05$ [91]. Putative functions were assigned to the differentially expressed transcripts following homology searches using the NCBI, Basic Local Alignment Search Tool (BLAST) against the NCBI non-redundant (nr) database and motif identification using IPS within the Blast2GO package (Version 5) [87].

\section{Phylogenetic assessment of the predicted protein sequences of the $P$. ovis DFP2-like genes}

Multiple sequence alignments were generated using a progressive alignment algorithm within the CLC Genomics Workbench (Version 12, Qiagen Ltd) [92]. The multiple sequence alignments were used to produce phylogenetic trees based on a maximum likelihood phylogeny method with neighbour joining tree construction and Jukes-Cantor substitution model with 100 bootstraps.

Interactive web-based presentation of the $P$. ovis genome and gene expression atlas

$\mathrm{Ab}$ initio gene predictions and annotation of the $P$. ovis genome were performed using the gene prediction platform, EuGene, as previously described [18]. Predicted genes were functionally annotated through a combination of InterProScan and reciprocal best BLAST hits. Predicted secretion signals, transmembrane helices, and other functional domains were generated within PHOBIUS [93, 94]. The full annotation for each $P$. ovis gene is available within the Online Resource for Community Annotation of Eukaryotes
(OrcAE) along with gene expression (RNA-seq) data from the current study viewable as a gene expression atlas.

\section{Supplementary information}

Supplementary information accompanies this paper at https://doi.org/10. 1186/s12864-019-6082-6.

Additional file 1: Table S1. Total number of Illumina Solexa Hi-Seq reads and the percentage of reads pseudo-mapped for each sample to the $P$. ovis transcriptome. Data shown for each of the fifteen RNA samples from $P$. ovis life-cycle stages and for "fed" (F) and "starved" (S) mites. AF = adult females, $\mathrm{AM}=$ adult males, $\mathrm{L}=$ larvae, $\mathrm{P}=$ protonymph, $\mathrm{T}=$ tritonymph.

Additional file 2. Gene lists for each life cycle expression cluster.

Additional file 3. IDs and annotation for all genes attributed to each of the Venn/Euler diagram shown in Fig. 6.

Additional file 4. Gene IDs for all $P$. ovis genes attributed to each WHO/ IUIS allergen groups.

Additional file 5. Annotated lists of differentially expressed genes identified from each of the pairwise life-cycle stage comparisons.

\section{Acknowledgements}

The authors would like to thank the Gene Pool Next Generation Sequencing and Bioinformatics Service at the University of Edinburgh for the $P$. ovis mite transcriptome sequencing. We also acknowledge the excellent service provided by the Moredun Research Institute, Bioservices team.

\section{Authors' contributions}

STGB and SR contributed to study design, drafted the manuscript and performed the experiments. EJM, KB, FGN, RED, JCP, JD performed the experiments. AJN, RJW, TVL and YVdP contributed to the study design and drafting the manuscript. All authors read and approved the final manuscript.

\section{Funding}

This work was supported by the UK Department for Environment Food and Rural Affairs (Defra) under research projects OD0555 and OD0556 and also received financial support from the Scottish Government's Rural Affairs Food and Environment Strategic Research (RESAS) programme. The Moredun Research Institute is one of the Scottish Government's major research providers under the collective of the Scottish Environment, Food and Agriculture Research Institutes (SEFARI).

\section{Availability of data and materials}

The datasets generated and analysed during the current study are fully compliant with the MINISEQE guidelines and are deposited in the publicly accessible NCBI Sequence Read Archive (SRA) Database under the project accession number PRJNA521406. The $P$. ovis draft genome sequence is available at DDBJ/ENA/GenBank under the accession number PQWQ01000000. The full annotation of the P. ovis genome has been made publicly available via the Online Resource for Community Annotation of Eukaryotes (OrcAE) via the following link: https://bioinformatics.psb. ugent.be/orcae/

\section{Ethics approval and consent to participate}

All experiments were carried out under the authority of a UK Home Office Project License (PPL 70/8870) within the terms and conditions of the regulations of the UK Home Office Animals (Scientific Procedures) Act 1986 and the code of practice for the housing and care of animals bred, supplied, or used for scientific purposes. Ethical approval for the study was obtained from the Moredun Research Institute Experiments Committee [E03/17].

\section{Consent for publication}

Not applicable

\section{Competing interests}

The authors declare that they have no competing interests. 


\section{Author details}

${ }^{1}$ Moredun Research Institute, Pentlands Science Park, Bush Loan, Edinburgh, Midlothian EH26 OPZ, UK. ${ }^{2}$ Fera Science Ltd, Sand Hutton, York YO41 1LZ, UK. ${ }^{3}$ Department of Plant Biotechnology and Bioinformatics, Ghent University, Technologiepark 927, 9052 Ghent, Belgium. ${ }^{4} \mathrm{VIB}$ Center for Plant Systems Biology, Technologiepark 927, 9052 Ghent, Belgium. ${ }^{5}$ Bioinformatics Institute Ghent, Ghent University, 9052 Ghent, Belgium. ${ }^{6}$ Department of Plants and Crops, Ghent University, Coupure links 653, B-9000 Ghent, Belgium. ${ }^{7}$ Department of Biochemistry, Genetics and Microbiology, University of Pretoria, Private bag X20, Pretoria 0028, South Africa.

Received: 4 June 2019 Accepted: 5 September 2019 Published online: 23 October 2019

\section{References}

1. Kirkwood AC. History, biology and control of sheep scab. Parasitol Today. 1986;2:302-7.

2. Nieuwhof GJ, Bishop SC. Costs of the major endemic diseases of sheep in Great Britain and the potential benefits of reduction in disease impact. Anim Sci. 2005;81:23-9.

3. Nisbet AJ, Huntley JF. Progress and opportunities in the development of vaccines against mites, fleas and myiasis-causing flies of veterinary importance. Parasite Immunol. 2006;28:165-72.

4. Doherty E, Burgess S, Mitchell S, Wall R. First evidence of resistance to macrocyclic lactones in Psoroptes ovis sheep scab mites in the UK. Vet Rec. 2018;182:106.

5. Sweatman GK. On the life history and validity of the species in Psoroptes, a genus of mange mites. Can J Zool. 1958;36:905-29.

6. Bates PG. The biology of Psoroptes ovis, the sheep scab mite. In: Proceedings of the conference on sheep scab (Psoroptic Mange), Tralee, Co Kerry, Ireland; 1996. p. 27-9.

7. Lewis C. Update on sheep scab. In Pract. 1997;19:558-64.

8. O'Brien DJ, Gray JS, O'Reilly PF. Examination of possible transmission of sheep scab mite Psoroptes ovis between host species. Vet Res Commun. 1994;18:113-7.

9. DeLoach JR, Wright FC. Ingestion of rabbit erythrocytes containing $51 \mathrm{Cr}$ labeled hemoglobin by Psoroptes spp. (Acari: Psoroptidae) that originated on cattle, mountain sheep, or rabbits. J Med Entomol. 1981;18:345-8.

10. Mathieson BR, Lehane MJ. Ultrastructure of the alimentary canal of the sheep scab mite, Psoroptes ovis (Acari: Psoroptidae). Vet Parasitol. 2002;104:151-66.

11. Burgess ST, Frew D, Nunn F, Watkins CA, McNeilly TN, Nisbet AJ, et al. Transcriptomic analysis of the temporal host response to skin infestation with the ectoparasitic mite Psoroptes ovis. BMC Genomics. 2010;11:624.

12. van den Broek AH, Huntley JF. Sheep scab: the disease, pathogenesis and control. J Comp Pathol. 2003;128:79-91.

13. Hamilton KA, Nisbet AJ, Lehane MJ, Taylor MA, Billingsley PF. A physiological and biochemical model for digestion in the ectoparasitic mite, Psoroptes ovis (Acari: Psoroptidae). Int J Parasitol. 2003;33:773-85.

14. Kenyon F, Welsh M, Parkinson J, Whitton C, Blaxter ML, Knox DP. Expressed sequence tag survey of gene expression in the scab mite Psoroptes ovis--allergens, proteases and free-radical scavengers. Parasitology. 2003;126(Pt 5):451-60.

15. McNair CM, Billingsley PF, Nisbet AJ, Knox DP. Feeding-associated gene expression in sheep scab mites (Psoroptes ovis). Vet Res. 2010;41:16.

16. Burgess ST, Downing A, Watkins CA, Marr EJ, Nisbet AJ, Kenyon F, et al. Development of a cDNA microarray for the measurement of gene expression in the sheep scab mite Psoroptes ovis. Parasit Vectors. 2012;5:30.

17. He ML, Xu J, He R, Shen NX, Gu XB, Peng XR, et al. Preliminary analysis of Psoroptes ovis transcriptome in different developmental stages. Parasit Vectors. 2016:9:570.

18. Burgess STG, Bartley K, Marr EJ, Wright HW, Weaver RJ, Prickett JC, et al. Draft genome assembly of the sheep scab mite, Psoroptes ovis. Genome Announc. 2018;6. https://doi.org/10.1128/genomeA.00265-18.

19. Rider SD Jr, Morgan MS, Arlian LG. Draft genome of the scabies mite. Parasit Vectors. 2015;8:585.

20. Grbić M, Van Leeuwen T, Clark RM, Rombauts S, Rouzé P, Grbić V, et al. The genome of Tetranychus urticae reveals herbivorous pest adaptations. Nature. 2011;479:487-92.

21. Waldron R, McGowan J, Gordon N, McCarthy C, Mitchell EB, Doyle S, et al. Draft genome sequence of Dermatophagoides pteronyssinus, the European house dust mite. Genome Announc. 2017;5. https://doi.org/10.1128/ genomeA.00789-17.

22. Chan TF, Ji KM, Yim AK, Liu XY, Zhou JW, Li RQ, et al. The draft genome, transcriptome, and microbiome of Dermatophagoides farinae reveal a broad spectrum of dust mite allergens. J Allergy Clin Immunol. 2015;135:539-48.

23. Sterck L, Billiau K, Abeel T, Rouzé $P$, Van de Peer $Y$. ORCAE: online resource for community annotation of eukaryotes. Nat Methods. 2012;9:1041.

24. Yandell M, Ence D. A beginner's guide to eukaryotic genome annotation. Nat Rev Genet. 2012;13:329-42.

25. Sanders A, Froggatt P, Wall R, Smith KE. Life-cycle stage morphology of Psoroptes mange mites. Med Vet Entomol. 2000;14:131-41.

26. Bray NL, Pimentel H, Melsted P, Pachter L. Near-optimal probabilistic RNAseq quantification. Nat Biotechnol. 2016;34:525-7.

27. van Noort V, Snel B, Huynen MA. Predicting gene function by conserved coexpression. Trends Genet. 2003;19:238-42.

28. Klomp JA, Furge KA. Genome-wide matching of genes to cellular roles using guilt-by-association models derived from single sample analysis. BMC Res Notes. 2012:5:370.

29. O'Hara L, Livigni A, Theo T, Boyer B, Angus T, Wright D, et al. Modelling the Structure and Dynamics of Biological Pathways. PLoS Biol. 2016;14:e1002530.

30. Connallon T, Knowles LL. Intergenomic conflict revealed by patterns of sexbiased gene expression. Trends Genet. 2005;21:495-9.

31. Rinn JL, Snyder M. Sexual dimorphism in mammalian gene expression. Trends Genet. 2005;21:298-305.

32. Parisi M, Nuttall R, Edwards P, Minor J, Naiman D, Lü J, et al. A survey of ovary-, testis-, and soma-biased gene expression in Drosophila melanogaster adults. Genome Biol. 2004;5:R40.

33. Tall AR, Yvan-Charvet $L$, Terasaka N, Pagler T, Wang N. HDL, ABC transporters, and cholesterol efflux: implications for the treatment of atherosclerosis. Cell Metab. 2008:7:365-75.

34. Wenzel JJ. ABC A-subclass proteins: Gatekeepers of cellular phospho- and sphingolipid transport. Front Biosci. 2007;12:3177.

35. Dermauw $W$, Van Leeuwen $T$. The $A B C$ gene family in arthropods: comparative genomics and role in insecticide transport and resistance. Insect Biochem Mol Biol. 2014;45:89-110.

36. Sinclair AN, Filan SJ. Lipid ingestion from sheep epidermis by Psoroptes ovis (Acari: Psoroptidae). Vet Parasitol. 1989;31:149-64.

37. Rafferty DE, Gray JS. The feeding behaviour of Psoroptes spp. mites on rabbits and sheep. J Parasitol. 1987;73:901-6.

38. Swe PM, Fischer K. A scabies mite serpin interferes with complementmediated neutrophil functions and promotes staphylococcal growth. PLoS Negl Trop Dis. 2014;8:e2928.

39. Lin J, Li M, Liu Y, Jiang C, Wu Y, Wang Y, et al. Expression, purification and characterization of Der $\mathrm{f} 27$, a new allergen from dermatophagoides farinae. Am J Transl Res. 2015;7:1260-70.

40. Hoffmann W, Hauser F. The P-domain or trefoil motif: a role in renewal and pathology of mucous epithelia? Trends Biochem Sci. 1993;18:239-43.

41. Radauer C, Bublin M, Wagner S, Mari A, Breiteneder H. Allergens are distributed into few protein families and possess a restricted number of biochemical functions. J Allergy Clin Immunol. 2008;121:847-52.e7.

42. Movérare $\mathrm{R}$, Larhammar $\mathrm{M}$, Everberg $\mathrm{H}$, Larsson $\mathrm{H}$, Poorafshar $\mathrm{M}$. Identification of Heat-Shock Protein $70 \mathrm{kDa}$ as a New Important Allergen in Sesame Seed. J Allergy Clin Immunol. 2010;125(2, Supplement 1):AB227.

43. Garrido PM, Porrini MP, Damiani N, Ruffinengo S, Martínez Noël GMA, Salerno G, et al. Heat shock proteins in Varroa destructor exposed to heat stress and in-hive acaricides. Exp Appl Acarol. 2018;76:421-33.

44. Evans GO, Sheals JG, Macfarlane D, et al. The terrestrial Acari of the British Isles. An introduction to their morphology, biology and classification. Volume I. Introduction and biology. 1961. https://www.cabdirect.org/ cabdirect/abstract/19621000049.

45. Parisi M, Nuttall R, Naiman D, Bouffard G, Malley J, Andrews J, et al. Paucity of genes on the Drosophila $X$ chromosome showing male-biased expression. Science. 2003;299:697-700.

46. Ranz JM, Castillo-Davis CI, Meiklejohn CD, Hartl DL. Sex-dependent gene expression and evolution of the Drosophila transcriptome. Science. 2003;300:1742-5.

47. Begun DJ, Whitley P, Todd BL, Waldrip-Dail HM, Clark AG. Molecular population genetics of male accessory gland proteins in Drosophila. Genetics. 2000;156:1879-88. 
48. Swanson WJ, Clark AG, Waldrip-Dail HM, Wolfner MF, Aquadro CF. Evolutionary EST analysis identifies rapidly evolving male reproductive proteins in Drosophila. Proc Natl Acad Sci U S A. 2001;98:7375-9.

49. Swanson WJ, Vacquier VD. Reproductive protein evolution. Annu Rev Ecol Syst. 2002;33:161-79. https://doi.org/10.1146/annurev.ecolsys.33. 010802.150439 .

50. Haerty W, Jagadeeshan S, Kulathinal RJ, Wong A, Ravi Ram K, Sirot LK, et al. Evolution in the fast lane: rapidly evolving sex-related genes in Drosophila. Genetics. 2007:177:1321-35.

51. Liu $X-Y$, Yang KY, Wang M-Q, Kwok JS-L, Zeng $X$, Yang $Z$, et al. Highquality assembly of Dermatophagoides pteronyssinus genome and transcriptome reveals a wide range of novel allergens. J Allergy Clin Immunol. 2018;141:2268-71.e8.

52. Walkley NA, Demaine AG, Malik AN. Cloning, structure and mRNA expression of human Cctg, which encodes the chaperonin subunit CCTY. Biochem J. 1996:313:381-9.

53. Willison KR. The structure and evolution of eukaryotic chaperonincontaining TCP-1 and its mechanism that folds actin into a protein spring Biochem J. 2018:475:3009-34

54. Mika A, Bergström F, Reynolds S, Willis C, Pickering D, Pike R, et al. Novel scabies mite serpins inhibit the three pathways of the human complement system. Mol Immunol. 2011;48:1698.

55. Reithofer M, Jahn-Schmid B. Allergens with protease activity from house dust mites. Int J Mol Sci. 2017;18. https://doi.org/10.3390/ijms18071368.

56. Lee AJ, Machell J, Van Den Broek AH, Nisbet AJ, Miller HR, Isaac RE, et al. Identification of an antigen from the sheep scab mite, Psoroptes ovis, homologous with house dust mite group I allergens. Parasite Immunol. 2002:24:413-22

57. Trompette A, Divanovic S, Visintin A, Blanchard C, Hegde RS, Madan R, et al. Allergenicity resulting from functional mimicry of a Toll-like receptor complex protein. Nature. 2009;457:585-8.

58. Nunn FG, Burgess STG, Innocent G, Nisbet AJ, Bates P, Huntley JF. Development of a serodiagnostic test for sheep scab using recombinant protein Pso o 2. Mol Cell Probes. 2011;25:212-8.

59. Pulsawat $P$, Theeraapisakkun $M$, Nony $E$, Le Mignon M, Jain K, Buaklin A, et al. Characterization of the house dust mite allergen Der $\mathrm{p} 21$ produced in Pichia pastoris. Protein Expr Purif. 2014;101:8-13.

60. ElRamlawy KG, Fujimura T, Aki T, Okada A, Suzuki T, Abe T, et al. Prominent IgE-binding and cytokine-inducing capacities of a newly cloned N-terminal region of Der $f 14$, an apolipophorin-like house dust mite allergen. J Biochem. 2018;163:51-60.

61. Whitten MMA, Tew IF, Lee BL, Ratcliffe NA. A novel role for an insect apolipoprotein (Apolipophorin III) in $\beta$-1,3-glucan pattern recognition and cellular encapsulation reactions. J Immunol. 2004;172:2177-85.

62. Pruett $\mathrm{JH}$. Identification and purification of a $16-\mathrm{kDa}$ allergen from Psoroptes ovis (Acarina: Psoroptidae). J Med Entomol. 1999;36:544-50.

63. Radauer C, Nandy A, Ferreira F, Goodman RE, Larsen JN, Lidholm J, et al. Update of the WHO/IUIS Allergen Nomenclature Database based on analysis of allergen sequences. Allergy. 2014;69:413-9.

64. Pomés A, Davies JM, Gadermaier G, Hilger C, Holzhauser T, Lidholm J, et al WHO/IUIS allergen nomenclature: providing a common language. Mo Immunol. 2018;100:3-13.

65. Fujimura T, Aki T, Isobe T, Matsuoka A, Hayashi T, Ono K, Kawamoto S. Der f 35: An MD-2-like house dust mite allergen that cross-reacts with Der $f 2$ and Pso o 2. Allergy. 2017;72(11):1728-36. https://doi.org/10.1111/all.13192.

66. Babicki S, Arndt D, Marcu A, Liang Y, Grant JR, Maciejewski A, et al. Heatmapper: web-enabled heat mapping for all. Nucleic Acids Res. 2016;44:W147-53.

67. Nisbet AJ, Billingsley PF. A comparative survey of the hydrolytic enzymes of ectoparasitic and free-living mites. Int J Parasitol. 2000;30:19-27.

68. Kenyon F, Knox D. The proteinases of Psoroptes ovis, the sheep scab mite-their diversity and substrate specificity. Vet Parasitol. 2002;105:317-25.

69. Sappington TW, Raikhel AS. Molecular characteristics of insect vitellogenins and vitellogenin receptors. Insect Biochem Mol Biol. 1998;28:277-300.

70. Huntley JF, Machell J, Nisbet AJ, Van den Broek A, Chua KY, Cheong N, et al. Identification of tropomyosin, paramyosin and apolipophorin/vitellogenin as three major allergens of the sheep scab mite, Psoroptes ovis. Parasite Immunol. 2004;26:335-42.

71. Thomas WR, Smith W-A, Hales BJ, Mills KL, O'Brien RM. Characterization and immunobiology of house dust mite allergens. Int Arch Allergy Immunol. 2002;129:1-18.
72. Ligoxygakis $\mathrm{P}$, Roth $\mathrm{S}$, Reichhart J-M. A serpin regulates dorsal-ventral axis formation in the Drosophila embryo. Curr Biol. 2003;13:2097-102.

73. Prevot P-P, Beschin A, Lins L, Beaufays J, Grosjean A, Bruys L, et al. Exosites mediate the anti-inflammatory effects of a multifunctional serpin from the saliva of the tick Ixodes ricinus. FEBS J. 2009;276:3235-46.

74. Páleníková J, Lieskovská J, Langhansová H, Kotsyfakis M, Chmelař J, Kopecký J. Ixodes ricinus salivary serpin IRS-2 affects Th17 differentiation via inhibition of the interleukin-6/STAT-3 signaling pathway. Infect Immun. 2015;83:1949-56.

75. Tirloni L, Seixas A, Mulenga A, Vaz I da S Jr, Termignoni C. A family of serine protease inhibitors (serpins) in the cattle tick Rhipicephalus (Boophilus) microplus. Exp Parasitol. 2014;137:25-34.

76. Misra S, Hecht P, Maeda R, Anderson KV. Positive and negative regulation of Easter, a member of the serine protease family that controls dorsal-ventral patterning in the Drosophila embryo. Development. 1998;125:1261-7.

77. Soulsby EJL, et al. Helminths, arthropods and protozoa of domesticated animals. 1968. https://www.cabdirect.org/cabdirect/ abstract/19682902735.

78. Xing P, Yu H, Li M, Xiao X, Jiang C, Mo L, et al. Characterization of arginine kinase, anovel allergen of dermatophagoides farinae (Der $f$ 20). Am J Transl Res. 2015;7:2815-23.

79. Ellington WR. Evolution and physiological roles of phosphagen systems. Annu Rev Physiol. 2001:63:289-325.

80. Strong SJ, Ellington WR. Isolation and sequence analysis of the gene for arginine kinase from the chelicerate arthropod, Limulus polyphemus: insights into catalytically important residues. Biochim Biophys Acta. 1995;1246:197-200.

81. Li W, Cowley A, Uludag M, Gur T, McWilliam H, Squizzato S, et al. The EMBLEBI bioinformatics web and programmatic tools framework. Nucleic Acids Res. 2015;43:W580-4.

82. Chruszcz M, Chapman MD, Vailes LD, Stura EA, Saint-Remy J-M, Minor W, et al. Crystal structures of mite allergens Der $f 1$ and Der $p 1$ reveal differences in surface-exposed residues that may influence antibody binding. J Mol Biol. 2009;386:520-30.

83. Robinson MD, McCarthy DJ, Smyth GK. edgeR: a Bioconductor package for differential expression analysis of digital gene expression data. Bioinformatics. 2010;26:139-40.

84. Byrne BM, Gruber M, Ab G. The evolution of egg yolk proteins. Prog Biophys Mol Biol. 1989:53:33-69.

85. Lee AJ, Huntley J, Van den Broek A, Coates D, Elwyn Isaac R. Expression and characterisation of a Psoroptes ovis glutathione S-transferase. Vet Parasitol. 2002;105:49-63.

86. Livigni A, O'Hara L, Polak ME, Angus T, Wright DW, Smith LB, et al. A graphical and computational modeling platform for biological pathways. Nat Protoc. 2018;13:705-22.

87. Gotz S, Garcia-Gomez JM, Terol J, Williams TD, Nagaraj SH, Nueda MJ, et al. High-throughput functional annotation and data mining with the Blast2GO suite. Nucleic Acids Res. 2008:36:3420-35.

88. Heberle H, Meirelles GV, da Silva FR, Telles GP, Minghim R. InteractiVenn: a web-based tool for the analysis of sets through Venn diagrams. BMC Bioinformatics. 2015;16:169

89. McCarthy DJ, Chen Y, Smyth GK. Differential expression analysis of multifactor RNA-Seq experiments with respect to biological variation. Nucleic Acids Res. 2012;40:4288-97.

90. Robinson MD, Oshlack A. A scaling normalization method for differential expression analysis of RNA-seq data. Genome Biol. 2010;11:R25.

91. Benjamini $Y$, Hochberg $Y$. Controlling the false discovery rate: a practical and powerful approach to multiple testing. J R Stat Soc Ser B Stat Methodol. 1995:57:289-300.

92. Feng DF, Doolittle RF. Progressive sequence alignment as a prerequisite to correct phylogenetic trees. J Mol Evol. 1987;25:351-60.

93. Kall L, Krogh A, Sonnhammer EL. A combined transmembrane topology and signal peptide prediction method. J Mol Biol. 2004:338:1027-36.

94. Jones P, Binns D, Chang HY, Fraser M, Li W, McAnulla C, et al InterProScan 5: genome-scale protein function classification. Bioinformatics. 2014:30:1236-40.

\section{Publisher's Note}

Springer Nature remains neutral with regard to jurisdictional claims in published maps and institutional affiliations. 